\title{
Latin Square Three-Dimensional Ball Plate (A Practical Approach to Evaluation of Coordinate Measuring Machine Capability)
}

Published October 1981

By L. L. Jones

Topical Report

Prepared for the United States Department of Energy Under Contract Number DE-AC04-76-DP00613. 


\section{DISCLAIMER}

This report was prepared as an account of work sponsored by an agency of the United States Government. Neither the United States Government nor any agency Thereof, nor any of their employees, makes any warranty, express or implied, or assumes any legal liability or responsibility for the accuracy, completeness, or usefulness of any information, apparatus, product, or process disclosed, or represents that its use would not infringe privately owned rights. Reference herein to any specific commercial product, process, or service by trade name, trademark, manufacturer, or otherwise does not necessarily constitute or imply its endorsement, recommendation, or favoring by the United States Government or any agency thereof. The views and opinions of authors expressed herein do not necessarily state or reflect those of the United States Government or any agency thereof. 


\section{DISCLAIMER}

Portions of this document may be illegible in electronic image products. Images are produced from the best available original document. 
This report was prepared as an account of work sponsored by the United States Government. Neither the United States nor the United States Department of Energy, nor any of their employees, nor any of their contractors, subcontractors, or their employees, makes any warranty, express or implied, or assumes any legal liability or responsibility for the accuracy, completeness or usefulness of any information, apparatus, product or process disclosed, or represents that its use would not infringe privately owned rights.

Printed in the United States of America

Available From the National Technical Information Service, U.S. Department of Commerce, 5285 Port Royal Road, Springfield, Virginia 22161.

Price: Microfiche $\$ 3.00$

Paper Copy $\$ 4.50$ 
$\mathrm{BDX}-613-2682$

Distribution Category UC-32

LATIN SQUARE THREE-DIMENSIONAL BALL PLATE

(A Practical Approach to Evaluation of Coordinate Measuring Machine Capability)

By L. L. Jones

Published October 1981

Topical Report

This book was prepared as an account of work sponsored by an ayency of the United States Governimens. Neither the United States Government nor any agency thereof, nor atty of their emplovets. makes an warranty, express or implied, of assumes any legal liability of responsibility for the accuracy. completeness, ar usefulness of any intormation. apparatus. product. or process disclosed. or

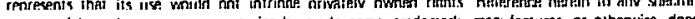

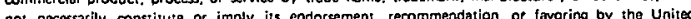

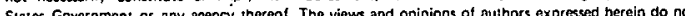

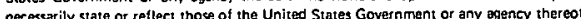

Technical Communications 
LATIN SQUARE THREE-DIMENSIONAL BALL PLATE (A Practical Approach to Evaluation of Coordinate Measuring Machine Capability)

BDX-613-2682, Topical Report, Published October 1981

Prepared by L. L. Jones

Electronic coordinate measuring machines (CMM) represent the state-of-the-art in automatic three-dimensional measuring equipment. Current techniques for determining measurement capability of CMM are complex. A Latin square three-dimensional ball plate has been developed to evaluate the measurement capability of a $\mathrm{CMM}$ in three dimensions. The unique allocation of tooling balls in an XYZ space permits data to be obtained that is balanced statistically and can be analyzed quickly by using the analysis of variance techniques for a Latin square experimental design. The analysis of this data is used to determine quantitative measures of the precision and systematic error of CMM in three dimensions and to identify sources of error in machine geometry. This ball plate currently is used to determine CMM capability and to identify source(s) of error in machine geometry. This device requires 70 percent less time than some conventional techniques to estimate CMM capability in three dimensions.

$\mathrm{DDK}: \mathrm{TR} 10 / \mathrm{h}$

This report was prepdred as an account of work sponsored by the United States Government. Neither the United States, nor the United States Department of Energy, nor any of their employees. nor any of their contractors, subcontractors, or their employees; makes any warranty. expressed or implied or essumes any legal liability or responsibility for the accuracy. completeness or usefulness of any information, apperatus, product, or process disclosed. or represents thet its use would not infringe privately owned rights.
The Bendix Corporation Kansas City Division P. O. Box 1159

Kansas City, Missouri 64141

A prime contractor with the United States Department of Energy under Contract Number DE-AC04-76-DPO0613 
CONTENTS

$\begin{array}{lll}\text { Section } & \text { Page }\end{array}$

SUMMARY. . . . . . . . . . . . . . . . . . . 6

DISCUSSION . . . . . . . . . . . . . . . 7

SCOPE AND PURPOSE. . . . . . . . . . . . . . . . . . . 7

ACTIVITY . . . . . . . . . . . . . . . 7

$\mathrm{CMM}$. . . . . . . . . . . . . . . . . . 7

Uses of LS3DBP . . . . . . . . . . . . . . . . 9

Measurement Capability . . . . . . . . . . . 9

Identification of Errors in CMM Geometry . . . . . 10

Description of the LS3DBP. . . . . . . . . . . . 11

Notation . . . . . . . . . . . . . . . . . . 18

Determining the Capability of CMMs . . . . . . . . 20

Identification of Errors in Machine Geometry . . . . 31

CONCLUSIONS . . . . . . . . . . . . . . . . . 35

REFERENCES . . . . . . . . . . . . . . . . . . . 39

APPENDICES :

A. INFORMATION ABOUT EXAMPLES OF COORDINATE MEASURING MACHINES . . . . . . . . . . . . . . . . . . . . . 40

B. CLASSIFICATIONS OF CMMS. . . . . . . . . . . 41 


\section{ILLUSTRATIONS}

Figure

Page

1 Latin Square Three-Dimensional Ball

Plate (R0748-01) . . . . . . . . . . . . . 8

2

A Four by Four Latin Square (R0748-02) . . .

3

Two-Dimensional Representation of a LatinSquare Three-Dimensional Ball Plate $(n=4)($ R0748-03) . . . . . . . . . . .

Sheldon Coordinate Measuring Machine (R0748-04) . . . . . . . . . . . . . . .

Close-Up of Probe at Point One (R0748-05). . .

6

LS3DBP on Table of CMM With Probe at Point $12($ R0748-06). . . . . . . . . .

LS3DBP on Table of CMM with Probe at Point Five (R0748-07). . . . . . . . . . .

Data From Table 2 in Latin Square Matrix (R0748-08). . . . . . . . . . .

9

Computational Technique to Compute Sum of Squares for a Four by Four Latin

Square (R0748-10). 


\section{TABLES}

Number

Page

Point Coordinates for Gage Master for the Three-Dimensional Measuring Machine. . . .

Sample Data to Demonstrate Analysis Technique for Data From LS3DBP . . . . . .

Generalized Analysis of Variance for Four by Four Latin Square with No Repeated Runs . . . . . . . . . . . . . . . . . .

Deviation From X Nominal ( $\mu$ in. ${ }^{2}$ ) . . . . . .

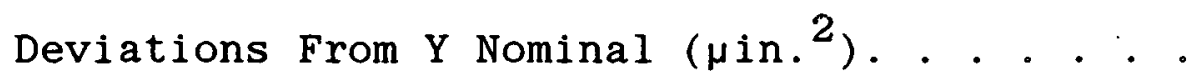

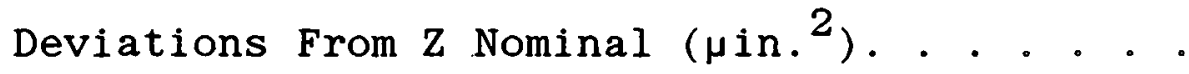

Summary of Analysis Results on Simulated Data From Cantilever Design CMM. . . . . .

Expanded Analysis of Variance for Deviations From X Nominal for Separation of Axis Sum of Squares Into Three Orthogonal Contrasts for Use in Identification of Sources of Error in Machine Geometry. . . . . . . .

Expanded Analysis of Variance for Deviations From $Y$ Nominal for Separation of Axis Sum of Squares Into Three Orthogonal Contrasts for Use in Identification of Sources of Error in Machine Geometry. . . . . . . .

Expanded Analysis of Variance for Deviations From Z Nominal for Separation of Axis Sum of Squares Into Three Orthogonal Contrasts for Use in Identification of Sources of Error in Machine Geometry. . . . . . . . 


\section{SUMMARY}

Electronic coordinate measuring machines (CMMs) represent the state-of-the-art in automatic three-dimensional measuring equipment. Current techniques to determine the measurement capability (precision plus systematic error) of a CMM are complex. Knowledge of this capability is important because it can affect machine productivity. A Latin square three-dimensional ball plate (LS3DBP) has been developed to obtain data that can be analyzed to determine the measurement capability of a CMM. The determination is achieved by a unique allocation of the heights of tooling balls in three dimensions. This allocation is achieved by using the concept of a Latin square experimental design. Data obtained from this configuration can be analyzed quickly by using the standard analysis of variance technique for a Latin square experimental design. The LS3DBP can reduce the time required to determine CMM measurement capability by 70 percent, compared to some conventional methods.

The information determined from the analysis is precision, systematic error, and identification of error sources in CMM geometry. This information provides a quantitative basis to determine whether the CMM can adequately measure a product and to assure that the decision regarding product acceptability has a high probability of being correcl. 


\section{DISCUSSION}

SCOPE AND PURPOSE

The Latin square three-dimensional ball plate (LS3DBP) is an innovation in the current technology of determining directly the measurement capability of coordinate measuring machines (CMMs). The advantage of this innovation to earlier art lies in the unique allocation of the heights of tooling balls in three dimensions (Figure 1). This allocation is achieved by using the concept of a Latin square experimental design. The heights of the tooling balls (cones) are arranged in a three-dimensional pattern. Data obtained from using this configuration are balanced statistically and can be analyzed quickly by using the standard analysis of variance technique for a Latin square experimental design. The analysis of data obtained by use of this device is used to determine quantitative measures of the precision and systematic error of CMMs in three dimensions and to identify error sources in machine geometry.

\section{ACTIVITY}

$\underline{\mathrm{CMM}}$

Electronic coordinate measuring machines represent the stateof-the-art in three-dimensional measuring equipment. Although thousands of CMMs are in use throughout the world, current techniques for determining precision and systematic error are complex and not readily available or used by most users and manufacturers. 


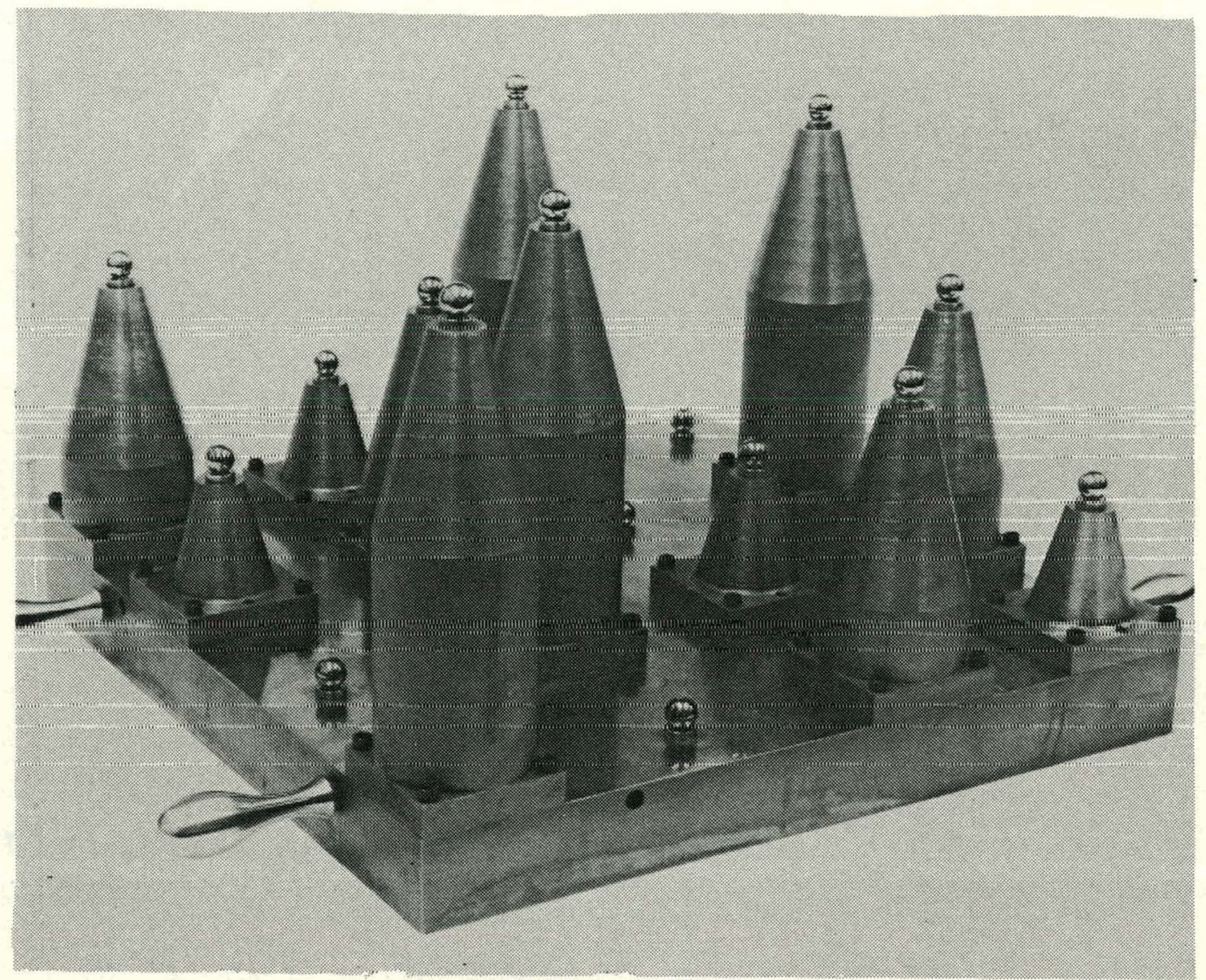

Figure 1. Latin Square Three-Dimensional Ball Plate

One report ${ }^{1}$ describes the significance and versatility of CMMs. Appendix A lists sources that can supply information about examples of CMMs. Classifications of CMMs are in Appendix B. Knowledge of CMM measurement capability is important because it can affect machine productivity, which will be demonstrated in a subsequent section. 


\section{Uses of LS3DBP}

The LS3DBP is used to obtain data that is analyzed by using the analysis of variance (AOV) technique to determine the measurement capability of a CMM and to identify source(s) of error in machine geometry. The analysis technique is simple, straightforward, and can be performed in about one hour by an individual with no background in statistics who uses a hand calculator. (The AOV computational procedure can also be programmed into the microprocessor interfaced with a CMM.) The LS3DBP can be used with any CMM with a working space that will accommodate its configuration. The information that can be determined through analysis of data from the LS3DBP follows.

\section{Measurement Capability}

Measurement capability (accuracy) of a coordinate measuring machine is characterized by precision and systematic error (bias), determined relative to a given calibrated fixture. Precision is a random (inherent) error in the measurement process of a CMM. This error is determined by the inability of the measurement process of a CMM to obtain the same values ( $X$ and/or $\mathrm{Y}$ and/or $\mathrm{Z}$ ) when the same point is measured more than once. The magnitude of this error may vary from one location to another within the working space of a CMM.

Systematic error (bias) is the difference between the true value of a characteristic and the average of repeated measurements of 
that characteristic. This study deals with systematic error that is caused by error in CMM geometry. Thus, systematic error is determined by bias introduced into the measurement process by movement along the $\mathrm{X}-, \mathrm{Y}-$, and $\mathrm{Z}$-axes. Other factors that may contribute to systematic error are environments, operators, and calibration error. These factors are not considered in this study and subsequent analyses. CMM measurement capability is variation in the measurement process that consists of precision plus systematic error. The characterization of this capability in this study is denoted by $\sigma^{2} \mathrm{CMM}$ and is a univariate representation of the observed variability in a three-dimensional space. This characterization provides the CMM user with a quantitative measure of the machine's measurement capability and a basis for determining whether a CMM can measure product adequately and for assuring that a decision regarding product acceptability has a high probability of being correct.

\section{Identification of Errors in CMM Geometry}

There are 21 sources of error in machine geometry that can introduce inaccuracy into the measurement process. Such inaccuracy results in misclassification of parts. (Misclassification means to accept a defective part or to reject a good part.) Each source of error produces a unique pattern of systematic errors (bias) in the deviations from nominal. These patterns may be characterized as to which axis movement affects the deviations, and the form of the effect on the deviations of that axis movement. An advantage 
of the LS3DBP is that the analysis of variance, from which quantitative estimates of the factors affecting machine capability are obtained, also can be used to identify sources of error in CMM geometry. Balanced data from an experimental design (Latin square) supply quantitative estimation of systematic bias, both in magnitude and form. A study involving simulated data from a cantilever design CMM indicates that the type of error can be identified by proper interpretation of the Latin square analysis of variance. ${ }^{2}$ (This will be discussed further in the section on identification of machine geometry error.) Rapid identification of the source of error reduces machine downtime for adjustments and thus increases productivity. Proper adjustment of the machine will reduce inaccuracy, which will in turn reduce the probability of misclassifying a part.

\section{Description of the LS3DBP}

Design Concept

Statistically balanced data are the most efficient means of obtaining information about a system. Other current methods of evaluating CMMs in three dimensions cannot adequately determine deviations from nominal values simultaneously in XYZ space that are balanced and that can be analyzed by using simple statistical techniques. The inadequacy of other methods exists because the associated devices must be moved to obtain balanced data. This movement introduces an additional source of variability into the measurement process that cannot be isolated. The data obtained 
by methods that require moving such devices fail to provide the best determination of the measurement capability of the CMM.

The LS3DBP overcomes this inadequacy caused by movement by using the concept of a Latin square experimental design in a single construction. A distinct advantage of the single construction is the reduction of CMM time required to obtain data to determine machine capability in XYZ space. Current methods can require the use of a two-dimensional ball plate evaluated three times at one location in the XY plane; then tilted on its longest side and evaluated three times in the $\mathrm{YZ}$ plane; then rotated $90^{\circ}$ and evaluated one time in the XZ plane. Tilting in ball plate on its side can be a potential source of error because the plate may deform in this position. The total time required is three and one-half hours ( 30 minutes for each evaluation). The LS3DBP requires no movement and provides simultaneous data in XYZ space. Two evaluations require only one hour (30 minutes for each evaluation), a 70 percent reduction in the time required to obtain data in $\mathrm{XYZ}$ space. This time savings increases CMM productivity.

A Latin square of side $\mathrm{n}$, or an $\mathrm{n}$ by $\mathrm{n}$ Latin square, is an arrangement of $\mathrm{n}$ letters, each repeated $\mathrm{n}$ times, in a square array of side $\mathrm{n}$ in such a manner that each letter appears only once in each row and column. An example of a 4 by 4 Latin square $(n=4)$ is shown in Figure 2. A two-dimensional representation of a LS3DBP ( $\mathrm{n}=4)$ is presented in Figure 3. The actual device is shown in Figure 1. 


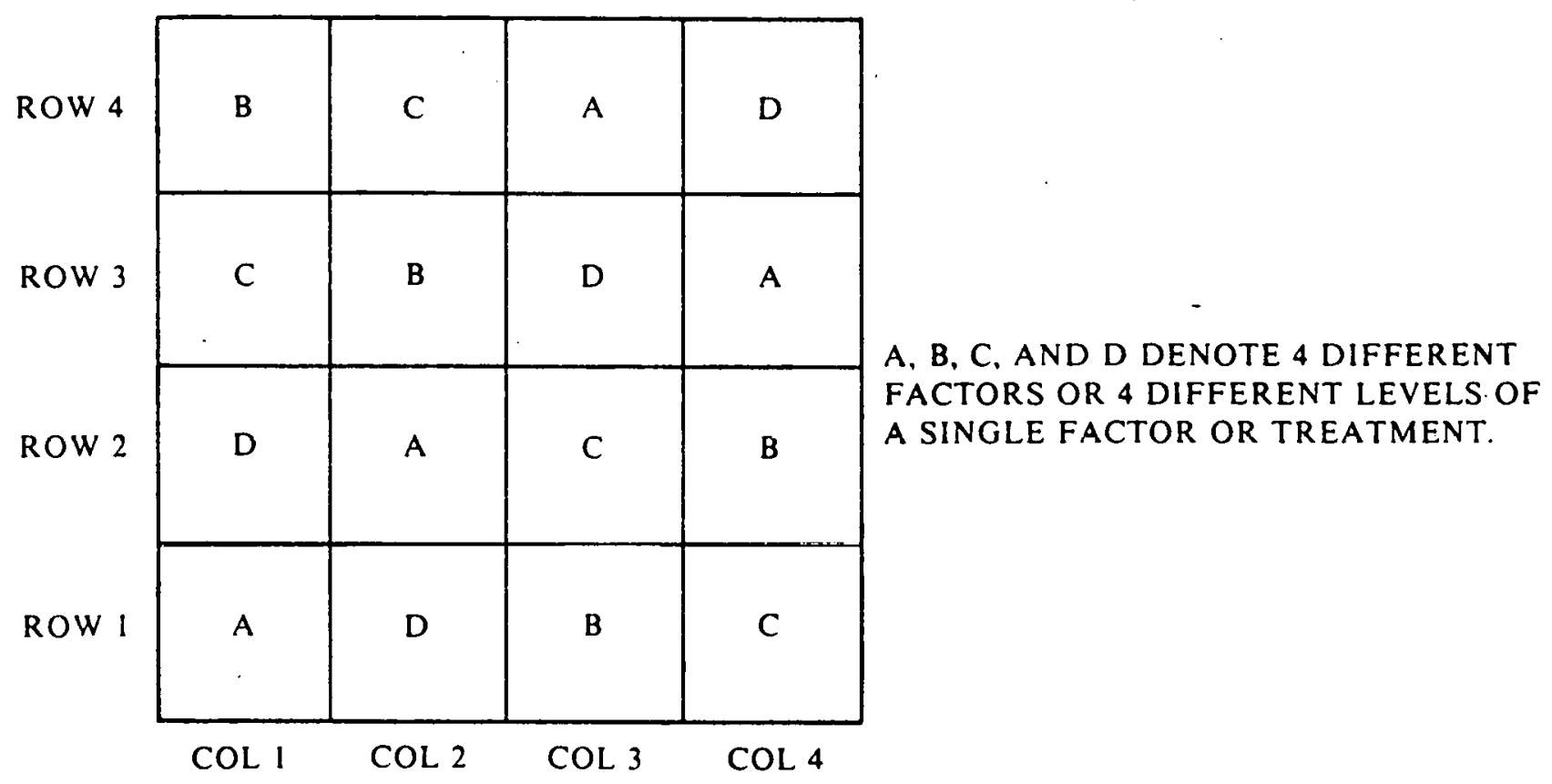

Figure 2. A Four by Four Latin Square

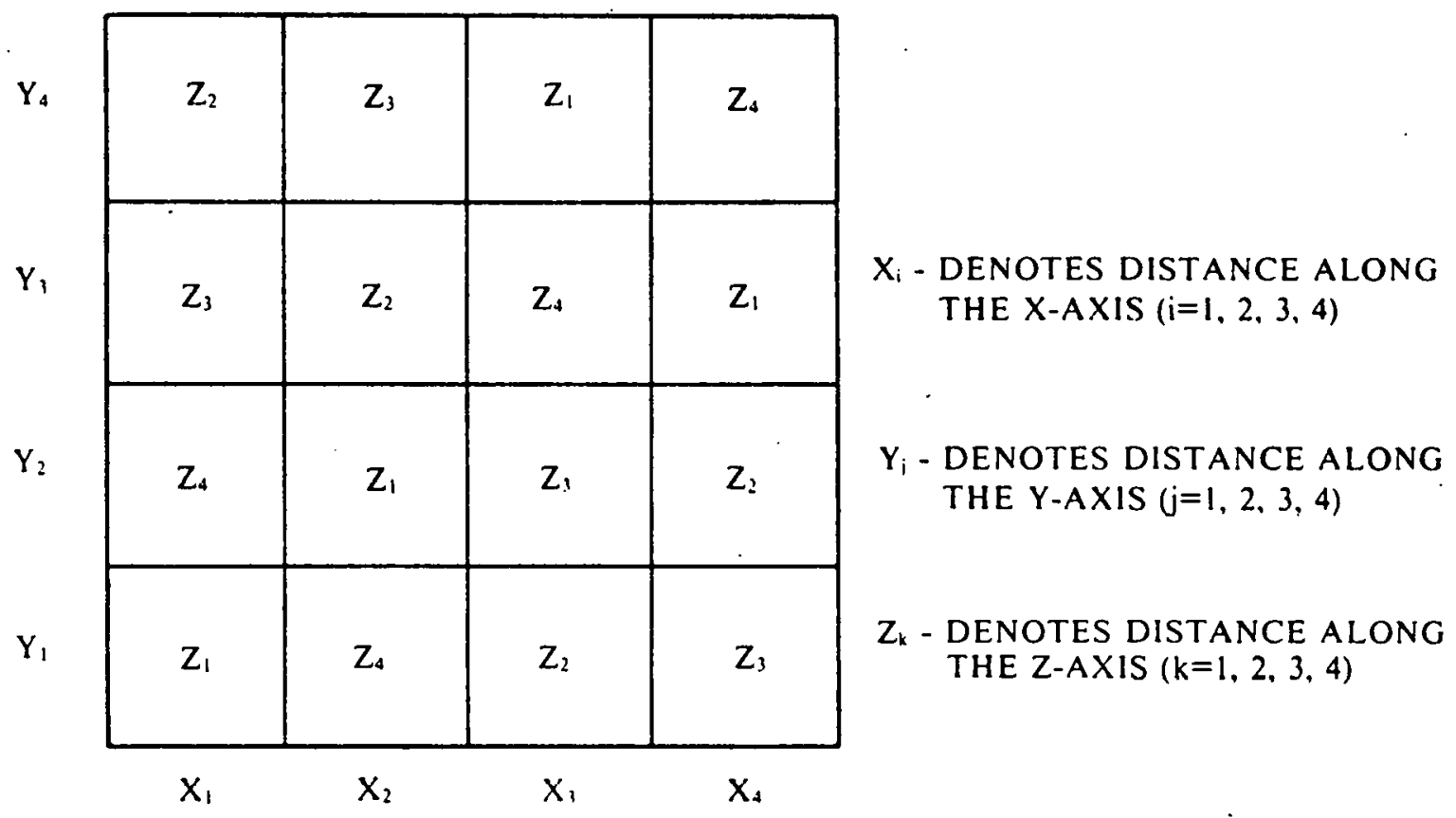

Figure 3. Two-Dimensional Representation of a Latin Square Three-Dimensional Rall. Plate 
Data obtained from a Latin square experimental design are balanced statistically and therefore can be analyzed by using the analysis of variance technique. (This technique will be illustrated in a subsequent section.) The balance concept implies that each level of each factor occurs equally often at each level of all remaining factors (Figure 2). The levels are axis distance and the factors are axes. In Figure 3 , the distance $X_{1}$ occurs exactly once with each distance of $Y\left(Y_{1}, Y_{2}, Y_{3}, Y_{4}\right)$, and with each distance of $z\left(z_{1}, z_{2}, z_{3}, z_{4}\right)$. The same is true for $x_{2}, x_{3}$, and $x_{4}$, and about $Y$ and $Z$. The advantage of the "balancing" concept is that determination of precision and accuracy for the analysis of data is applicable over the total range the three axes were moved.

\section{Physical Characteristics}

The dimensions of the LS3DBP is 18 by 18 by 11 in. ( $X$ by $Y$ by $Z$ ). These dimensions were selected to be compatible with CMMs at Bendix Kansas City. The cone heights are approximately 9, 6, and 3 in., respectively. The approximate height of the cored bench plate is 2 in. The bench plate and cones are made from the alloy meehanite to provide strength and stability. The cones are 3 in. in diameter at the base, and the walls are 1/2-in. thick. The cones have been cored and tapered to a 1-in. diameter at the top to reduce weight and to provide a solid base to maintain stability. The cones, grouped together (9-and 0-in. heights, and 3-and 6-in. heights), provide even weight distribution to each quadrant of 
the plate. (In Figure 3, $\mathrm{z}_{1}=9$ in.; $\mathrm{z}_{2}=6$ in., $\mathrm{z}_{3}=3$ in. and $z_{4}=0$ in. heights.) Each cone is fastened to the bench plate with four cap screws and two dowell pins.

The tooling balls are 5/8-in.-diameter tungsten carbide balls, grade five, and the uniformity between balls for diameter and sphericity measures within 0.000010 in. These balls are press-fit into the cones and bench plate. Holes have been drilled into each side of the plate to provide a location for plate temperature to be monitored. Other holes have been drilled at three locations in the bottom for feet to establish three points of surface contact to define a plane. If stress relief occurs, the deformation will always be consistent if the plate is resting on three points.

Determining the point coordinates of the tooling balls (Table 1) should be accomplished as accurately as possible. The point coordinates in Table 1 were obtained by using a Sheldon Coordinate Measuring Machine (Figure 4) and have been assigned an accuracy (uncertainty) of $\pm 0.000180 \mathrm{in.}$. It is expected that this uncertainty may be reduced by additional measurements of these coordinates. In practice, the estimate of coordinate accuracy would be combined with the estimates of precision and systematic error of the CMM to completely describe the accuracy of the CMM. The point coordinates become the nominal values. 
Table 1. Point Coordinates for Gage Master for the Three-Dimensional Measuring Machine ${ }^{*}$

\begin{tabular}{lrrr}
\hline $\begin{array}{l}\text { Point } \\
\text { Number }\end{array}$ & \multicolumn{1}{l}{$\begin{array}{l}\text { X Coordinates } \\
\text { (In.) }\end{array}$} & $\begin{array}{l}\text { Y Coordinates } \\
\text { (In.) }\end{array}$ & \multicolumn{1}{l}{$\begin{array}{l}\text { Z Coordinates } \\
\text { (In.) }\end{array}$} \\
\hline 1 & 0.000000 & 0.000000 & 0.000000 \\
2 & 5.000328 & 0.001090 & -8.999770 \\
3 & 10.001227 & -0.000417 & -2.999062 \\
4 & 15.001312 & 0.000000 & -5.999860 \\
5 & 0.000884 & 5.001870 & -8.999847 \\
6 & 5.000450 & 5.000704 & 0.000838 \\
7 & 10.003708 & 4.997918 & -5.998178 \\
8 & 15.001899 & 5.000274 & -2.998789 \\
9 & 0.000616 & 10.002434 & -5.999860 \\
10 & 5.001917 & 10.001809 & -2.998642 \\
11 & 10.001670 & 9.999530 & -8.997912 \\
12 & 15.002967 & 10.000883 & 0.000786 \\
13 & 0.001012 & 15.002576 & -3.000078 \\
14 & 5.000853 & 15.002546 & -6.001035 \\
15 & 10.000411 & 15.005720 & 0.000000 \\
16 & 15.001188 & 14.999662 & -9.000279 \\
\hline
\end{tabular}

\pm Accuracy of a given coordinate is \pm 0.000180 in.

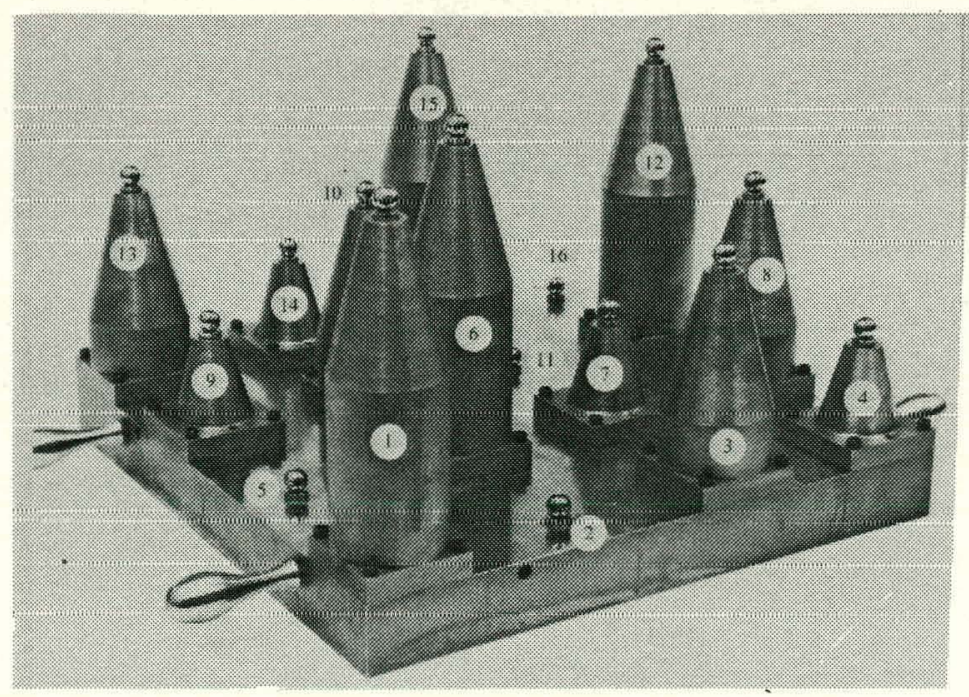




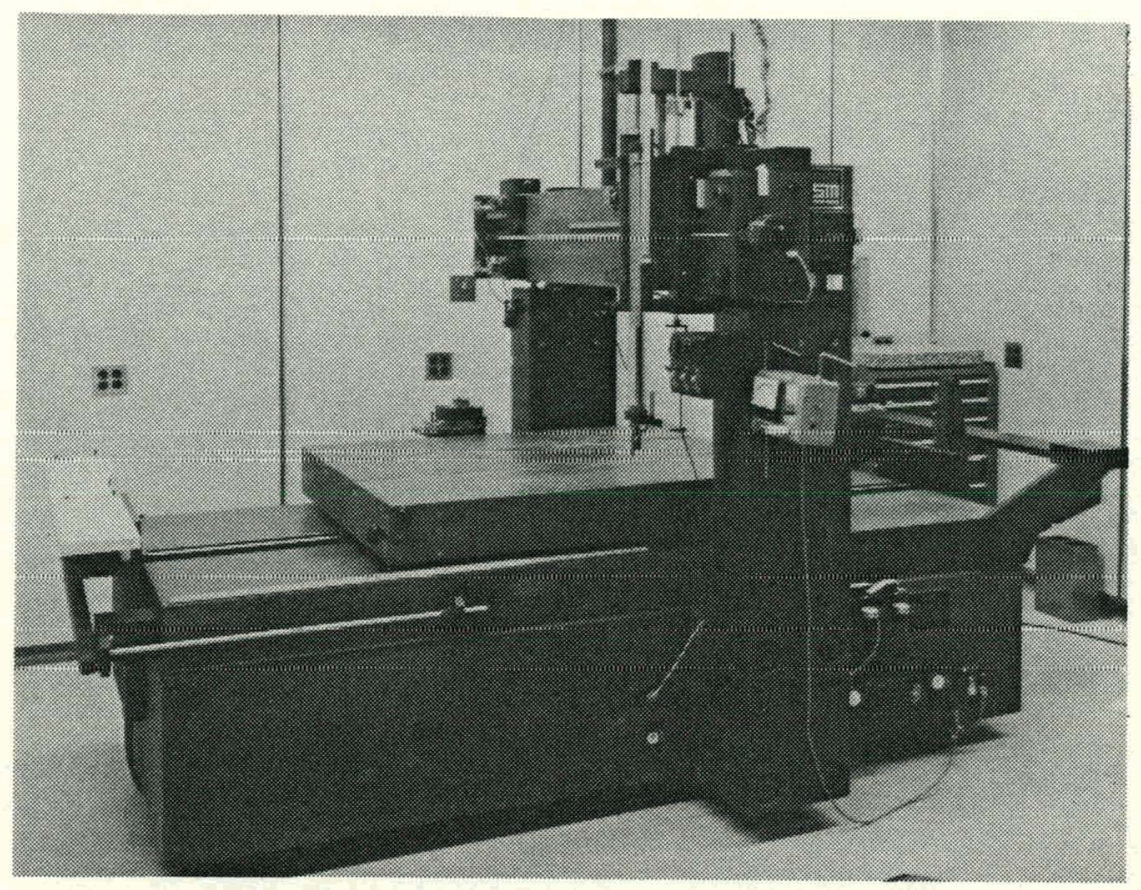

Figure 4. Sheldon Coordinate Measuring Machine

Data Collection

Data is collected by using the LS3DBP in the following manner. The device is placed on the table of a CMM (Figures 5 through 7). In this example, cone one is selected as the reference ball. The machine is started at this location. The probe is then moved from ball to ball in sequence $(1,2,3,4,5,6, \ldots, 16)$. At each ball location, $\mathrm{X}, \mathrm{Y}$, and $\mathrm{Z}$ observed values are obtained automatically. (In most machines the nominal values are read into the CMM computer so that deviations from nominal can be obtained automatically.) 




Figure 5. Close-Up of Probe at Point One

\section{Notation}

The following notation is used in this analysis.
$\sigma_{\mathrm{XDEV}}^{2}=$ A quantitative measure of variation of deviations from $\mathrm{X}$ nominal.

$\sigma_{\mathrm{YDEV}}^{2}=\mathrm{A}$ quantitative measure of variation of deviations from Y nominal. 


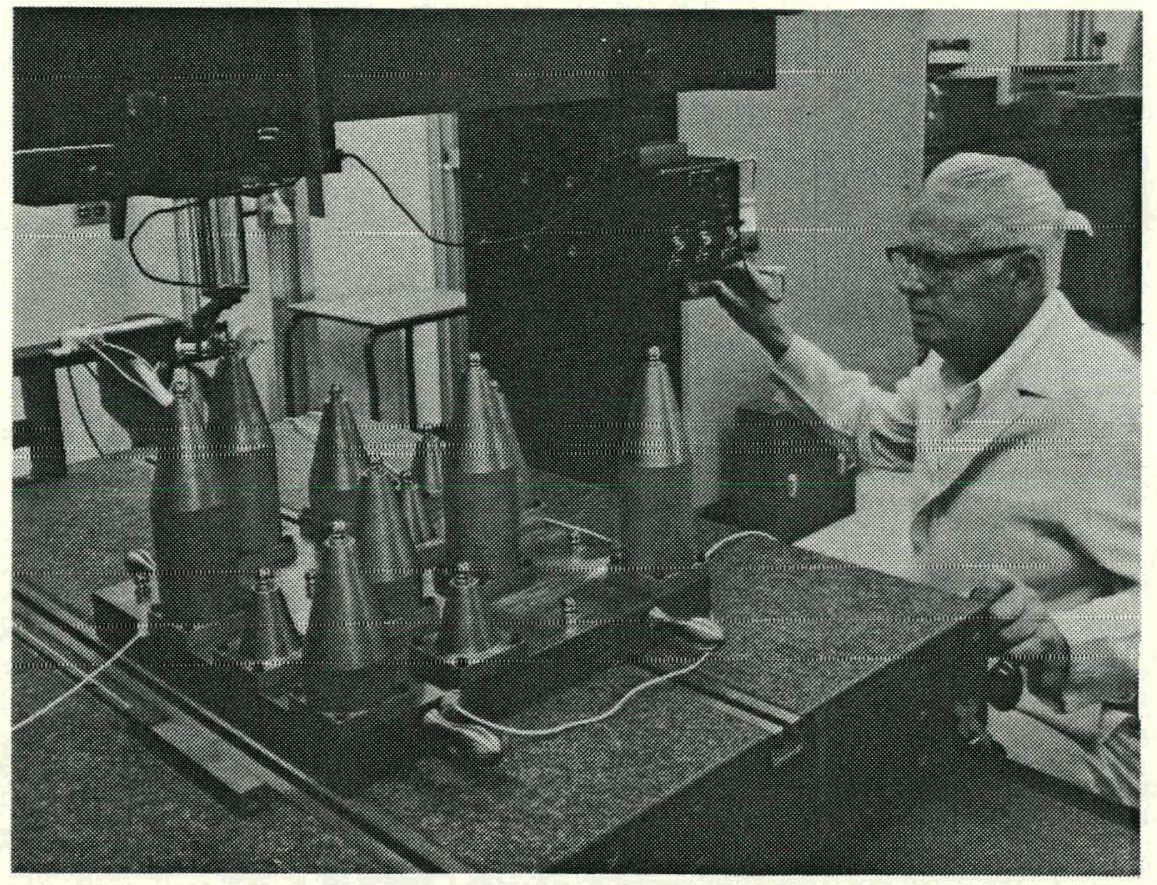

Figure 6. LS3DBP on Table of CMM With Probe at Point 12

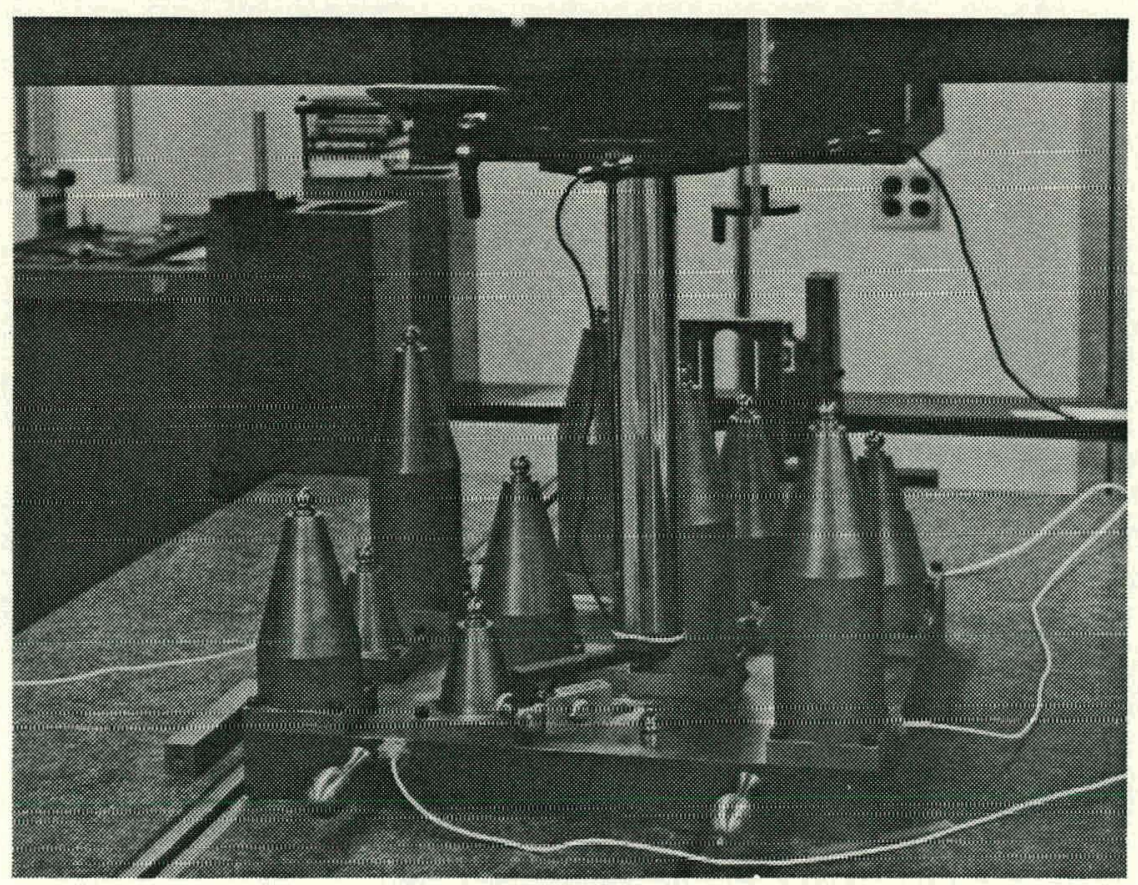

Figure 7. LS3DBP on Table of CMM With Probe at Point Five 
$\sigma_{\mathrm{ZDEV}}^{2}=$ A quantitative measure of variation of deviations from $\mathrm{Z}$ nominal.

$\sigma_{\mathrm{R}}^{2}=$ A quantitative measure of inherent random variation in the measuring process, determined by both repeated observations and/or residual interaction.

$\sigma_{\mathrm{X}}^{2}=$ A quantitative measure of systematic error in deviations from nominal because of movement of the probe along the $\mathrm{X}$-axis.

$\sigma_{\mathrm{Y}}^{2}=$ A quantitative measure of systematic error in deviations from nominal because of movement of the probe along the Y-axis.

$\sigma_{Z}^{2}=$ A quantitative measure of systematic error in deviations from nominal because of movement of the probe along the Z-axis .

$\sigma_{C M M}^{2}=$ A quantitative measure of capability of a coordinate measuring machine.

Determining the Capability of CMMs

An example of the analysis technique is presented. In Table 2 are a set of nominal values and sample data readings from a coordinate measuring machine obtained by using the LS3DBP. For 
Table 2. Sample Data to Demonstrate Analysis Technique for Data From LS3DBP

\begin{tabular}{|c|c|c|c|c|}
\hline $\mathrm{Pt}$ & Axis & $\begin{array}{l}\text { Nominal } \\
\text { Values }\end{array}$ & $\begin{array}{l}\text { Observed } \\
\text { Values }\end{array}$ & $\begin{array}{l}\text { OBS-NOM } \\
(\mu \text { in. })\end{array}$ \\
\hline 1 & $\begin{array}{l}\mathrm{X} \\
\mathrm{Y} \\
\mathrm{Z}\end{array}$ & $\begin{array}{l}0.000000 \\
0.000000 \\
0.000000\end{array}$ & $\begin{array}{l}0.000000 \\
0.000000 \\
0.000000\end{array}$ & $\begin{array}{l}0 \\
0 \\
0\end{array}$ \\
\hline 2 & $\begin{array}{l}\mathrm{X} \\
\mathrm{Y} \\
\mathrm{Z}\end{array}$ & $\begin{array}{r}4.999490 \\
0.001590 \\
-9.000310\end{array}$ & $\begin{array}{r}4.999500 \\
0.001590 \\
-9.000310\end{array}$ & $\begin{array}{r}10 \\
0 \\
0\end{array}$ \\
\hline 3 & $\begin{array}{l}\mathrm{X} \\
\mathrm{Y} \\
\mathrm{Z}\end{array}$ & $\begin{array}{l}10.000910 \\
-0.000450 \\
-2.999960\end{array}$ & $\begin{array}{l}10.000920 \\
-0.000490 \\
-2.999960\end{array}$ & $\begin{array}{r}10 \\
-40 \\
0\end{array}$ \\
\hline 4 & $\begin{array}{l}\mathrm{X} \\
\mathrm{Y} \\
\mathrm{Z}\end{array}$ & $\begin{array}{r}15.000750 \\
0.000020 \\
-6.001260\end{array}$ & $\begin{array}{l}15.000770 \\
-0.000020 \\
-6.001300\end{array}$ & $\begin{array}{r}20 \\
-40 \\
-40\end{array}$ \\
\hline 5 & $\begin{array}{l}\mathrm{X} \\
\mathrm{Y} \\
\mathrm{Z}\end{array}$ & $\begin{array}{r}0.000200 \\
5.002580 \\
-8.999640\end{array}$ & $\begin{array}{r}0.000220 \\
5.002580 \\
-8.999640\end{array}$ & $\begin{array}{r}20 \\
0 \\
0\end{array}$ \\
\hline 6 & $\begin{array}{l}\mathrm{X} \\
\mathrm{Y} \\
\mathrm{Z}\end{array}$ & $\begin{array}{l}5.000510 \\
5.000690 \\
0.000710\end{array}$ & $\begin{array}{l}5.000450 \\
5.000650 \\
0.000750\end{array}$ & $\begin{array}{r}-60 \\
-40 \\
40\end{array}$ \\
\hline 7 & $\begin{array}{l}\mathrm{X} \\
\mathrm{Y} \\
\mathrm{Z}\end{array}$ & $\begin{array}{r}10.003230 \\
4.998210 \\
-5.998780\end{array}$ & $\begin{array}{r}10.003210 \\
4.998170 \\
-5.998820\end{array}$ & $\begin{array}{l}-20 \\
-40 \\
-40\end{array}$ \\
\hline 8 & $\begin{array}{l}\mathrm{X} \\
\mathrm{Y} \\
\mathrm{Z}\end{array}$ & $\begin{array}{r}15.001730 \\
5.000260 \\
-2.999800\end{array}$ & $\begin{array}{r}15.001750 \\
5.000180 \\
-2.999800\end{array}$ & $\begin{array}{r}20 \\
-80 \\
0\end{array}$ \\
\hline 9 & $\begin{array}{l}\mathrm{X} \\
\mathrm{Y} \\
\mathrm{Z}\end{array}$ & $\begin{array}{r}0.000470 \\
10.002890 \\
-5.999370\end{array}$ & $\begin{array}{r}0.000490 \\
10.002890 \\
-5.999450\end{array}$ & $\begin{array}{r}20 \\
0 \\
-80\end{array}$ \\
\hline 10 & $\begin{array}{l}\mathrm{X} \\
\mathrm{Y} \\
\mathrm{Z}\end{array}$ & $\begin{array}{r}5.001930 \\
10.001950 \\
-2.998460\end{array}$ & $\begin{array}{r}5.001990 \\
10.001910 \\
-2.998580\end{array}$ & $\begin{array}{r}60 \\
-40 \\
-120\end{array}$ \\
\hline 11 & $\begin{array}{l}X \\
Y \\
Z\end{array}$ & $\begin{array}{r}10.001180 \\
9.999860 \\
-8.998270\end{array}$ & $\begin{array}{r}10.001200 \\
9.999940 \\
-8.998350\end{array}$ & $\begin{array}{l}20 \\
80 \\
80\end{array}$ \\
\hline 12 & $\begin{array}{l}\mathrm{X} \\
\mathrm{Y} \\
\mathrm{Z}\end{array}$ & $\begin{array}{r}15.003230 \\
10.000570 \\
0.000 .040\end{array}$ & $\begin{array}{r}15.003330 \\
10.000570 \\
0.000000\end{array}$ & $\begin{array}{r}100 \\
0 \\
-40\end{array}$ \\
\hline
\end{tabular}


Table 2 Continued. Sample Data to Demonstrate Analysis Technique for Data From LS3DBP

\begin{tabular}{rrrrr}
\hline Pt & Axis & $\begin{array}{l}\text { Nominal } \\
\text { Values }\end{array}$ & $\begin{array}{l}\text { Observed } \\
\text { Values }\end{array}$ & $\begin{array}{l}\text { OBS-NOM } \\
\text { ( } \mu \text { in.) }\end{array}$ \\
\hline 13 & X & 0.001140 & 0.001160 & 20 \\
& Y & 15.003010 & 15.002970 & -40 \\
& Z & -2.999210 & -2.999290 & -80 \\
14 & X & 5.000590 & 5.000650 & 60 \\
& Y & 15.002970 & 15.003010 & 40 \\
& Z & -6.000630 & -6.000710 & -80 \\
15 & X & 10.000670 & 10.000690 & 20 \\
& Y & 15.005610 & 15.005650 & 40 \\
& Z & 0.000040 & 0.000000 & -40 \\
16 & X & 15.000750 & 15.000770 & 20 \\
& Y & 15.000020 & 14.999940 & -80 \\
& Z & -9.000830 & -9.000940 & -110 \\
\hline
\end{tabular}

simplification in this study, the subsequent analyses assume that the nominal values in Table 2 are the true values. In practice, the true values are not known and the uncertainty of the point. coordinates would be combined with the measures of precision and systematic error of the CMM to completely describe the accuracy of the CMM. A statistical layout of the data is presented in Figure 8 for the $X, Y$, and $Z$ deviations from nominal. The objective of the analysis will be to estimate the precision and systematic error of the CMM being evaluated. For this study $\hat{\sigma}_{\mathrm{CMM}}^{2}=\hat{\sigma}_{\mathrm{XDEV}}^{2}+$ $\hat{\sigma}_{\mathrm{YDEV}}^{2}+\hat{\sigma}_{\mathrm{ZDEV}}^{2}$, where: 
$\hat{\sigma}_{\mathrm{XDEV}}^{2}=\hat{\sigma}_{\mathrm{X}}^{2}+\hat{\sigma}_{\mathrm{Y}}^{2}+\hat{\sigma}_{\mathrm{Z}}^{2}+\hat{\sigma}_{\mathrm{RX}}^{2}$;

$\hat{\sigma}_{\mathrm{YDEV}}^{2}=\hat{\sigma}_{\mathrm{X}}^{2}+\hat{\sigma}_{\mathrm{Y}}^{2}+\hat{\sigma}_{\mathrm{Z}}^{2}+\hat{\sigma}_{\mathrm{RY}}^{2} ;$ and

$\hat{\sigma}_{\mathrm{ZDEV}}^{2}=\hat{\sigma}_{\mathrm{X}}^{2}+\hat{\sigma}_{\mathrm{Y}}^{2}+\hat{\sigma}_{\mathrm{Z}}^{2}+\hat{\sigma}_{\mathrm{RZ}}^{2}$.

The symbol ^ denotes a value estimated from using observed data.

These components $\left(\sigma^{2}\right)$ are determined directly from the analysis of variance table. Table 3 shows a generalized analysis of variance table for a 4 by 4 Latin square. The computation procedure for data from the LS3DBP is also in Figure 9 for deviations from $X$ nominal. Table 4 shows the AOV table for deviations from $X$ nominal. The components used to determine machine capability are obtained by simple algebra, indicated by using the mean-square column and the expected mean-square column. For example, the estimate of precision is $\hat{\sigma}_{\mathrm{RX}}^{2}=1250 \mu \mathrm{in} .{ }^{2}$. To estimate the component caused by movement along the $\mathrm{Z}$-axis,

$\hat{\sigma}_{Z}^{2}=\frac{Z_{M S}-E_{M S}}{4}$.

If this value is negative, set $\hat{\sigma}_{Z}^{2}=0$. Similarly, 
DEVIATIONS FROM X NOMINAL ( $\mu$ IN.)

DISTANCE ALONG THE X-AXIS (INCHES)

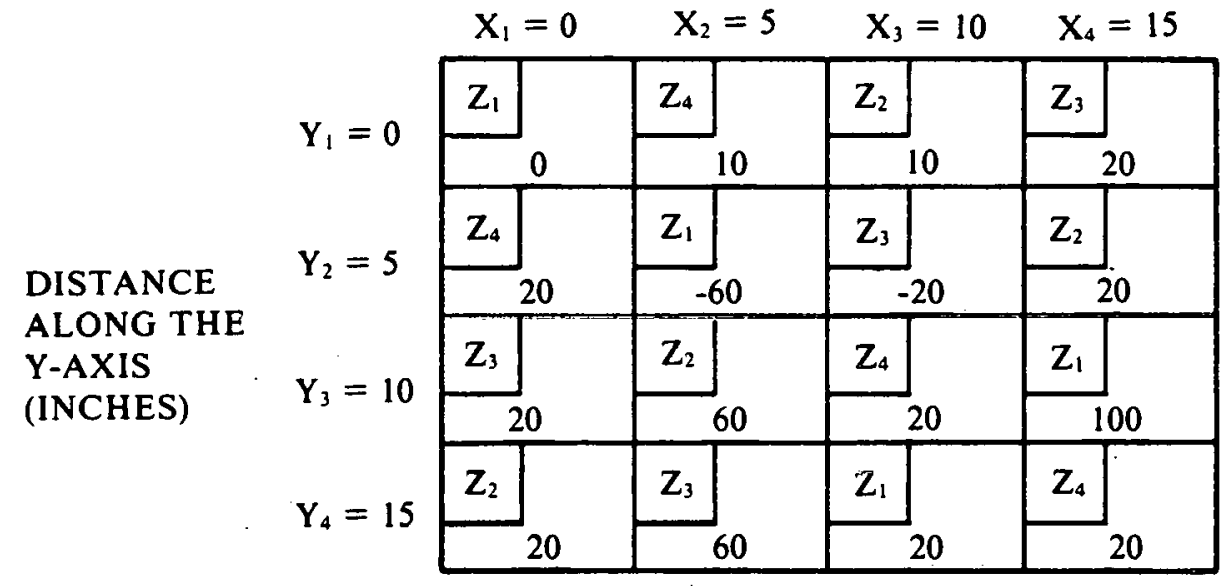

DEVIATIONS FROM Y NOMINAL $(\mu \mathrm{IN}$.

DISTANCE ALONG THE X-AXIS (INCHES)

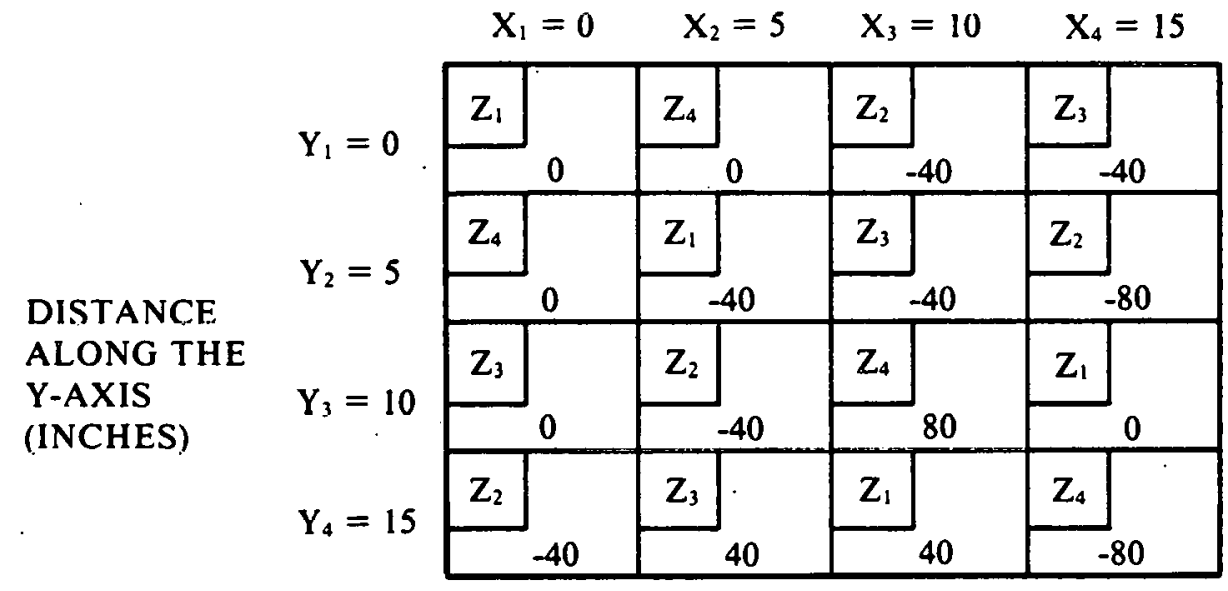

Figure 8. Data From Table 2 in Latin Square Matrix (Reference Weight $Z_{1}[9-$ in. cone $\left.]=0, Z_{2}=-3, Z_{3}=-6, Z_{4}-9.\right)$

$\hat{\sigma}_{Y}^{2}=\frac{Y_{M S}-E_{M S}}{4}$ 
DEVIATIONS FROM Z NOMINAL ( $\mu$ IN.)

DISTANCE ALONG THE X-AXIS (INCHES)

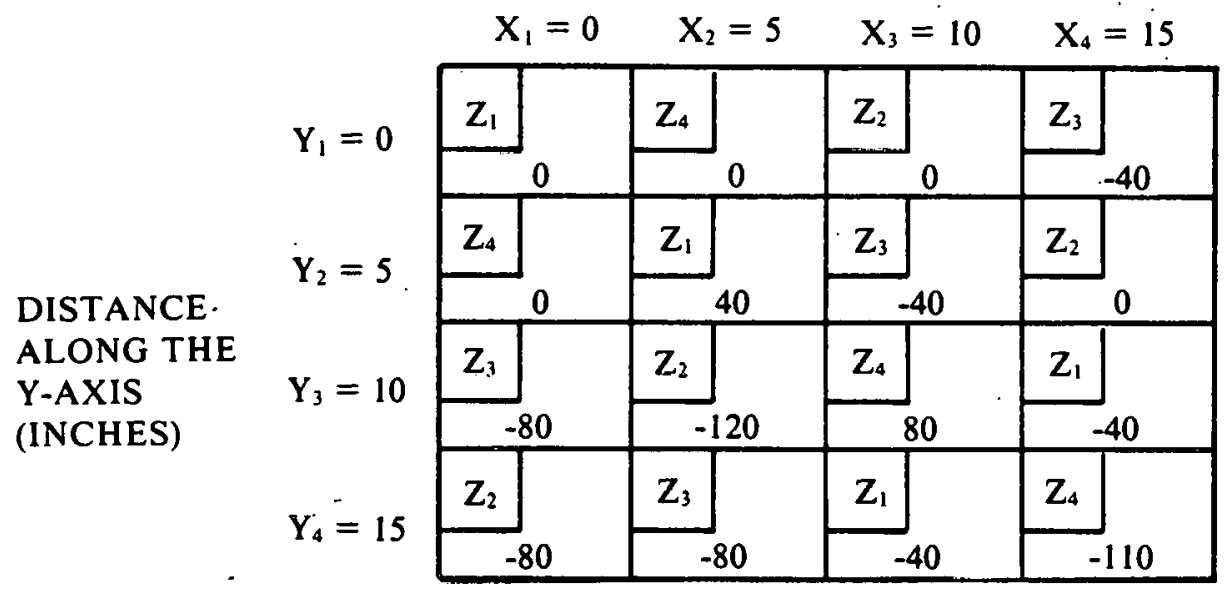

Figure 8 Continued. Data From Table 2 in Latin Square Matrix (Reference Height $\mathrm{Z}_{1}[9-\mathrm{in}$. cone $]=0$, $\left.\mathrm{Z}_{2}=-3, \mathrm{Z}_{3}=-6, \mathrm{Z}_{4}=-9.\right)$

and

$\hat{\sigma}_{X}^{2}=\frac{X_{M S}-E_{M S}}{4}$.

The analyses of deviations from $Y$ and $Z$ nominal are similar to those for deviations from $X$ nominal. Replace the deviations from $\mathrm{X}$ nominal in Figure 9 by the appropriate set of deviations and compute the AOVs. The AOVs are presented in Tables 5 and 6 for 


$$
\begin{aligned}
C & =\text { (Sum of Xdev) }{ }^{2} / 16=[(0)+(10)+(10)+\ldots+(20)]^{2} / 16=\frac{(320)^{2}}{16}=6400 \\
T s s & =\text { Sum of }(X d e v)^{2}-C=\left[(0)^{2}+(10)^{2}+(10)^{2}+\ldots+(20)^{2}\right]-6400=24600-6400=18200 \\
X s s & =\frac{X_{1}^{2}+X_{2}^{2}+X_{3}^{2}+X_{4}^{2}}{4}-C=\frac{(60)^{2}+(70)^{2}+(30)^{2}+(160)^{2}}{4}-C=8750-6400=2350 \\
Y s s & =\frac{Y_{1}^{2}+Y_{2}^{2}+X_{3}^{2}+X_{4}^{2}}{4}-C=\frac{(40)^{2}+(-40)^{2}+(200)^{2}+(120)^{2}}{4}-C=14400-6900=8000 \\
Z s s & =\frac{z_{1}^{2}+Z_{2}^{2}+Z_{3}^{2}+Z_{4}^{2}}{4}-C=\frac{(60)^{2}+(110)^{2}+(80)^{2}+(70)^{2}}{4}-C=6750-6400=350 \\
\text { Ess }= & T s s-X s s-Y s s-Z s s=18200-2350-8000-350=7500
\end{aligned}
$$

Where:

$\mathrm{x}_{1}=$ Sum of all deviation from $\mathrm{X}$ Nominal at $\mathrm{X}=0$

$$
x_{1}=0+20+20+20=60
$$

$x_{2}=$ Sum of all deviation from $X$ Nominal at $x=5$

$$
\mathrm{x}_{2}=10+(-60)+60+60=70
$$

$\mathrm{x}_{3}=10+(-20)+20+20=30$

$x_{4}=20+20+100+20=160$

$Y_{1}=$ Sum of all deviation from $X$ Nominal at $Y=0$

$$
\mathrm{Y}_{1}=0+10+10+20=40
$$

$\mathrm{Y}_{2}=20+(-60)+(-20)+20=-40$

$Y_{3}=20+60+20+100=200$

$Y_{4}=20+60+20+20=120$

$z_{1}=$ Sum of all deviation from $x$ Nominal at $z=$ Base Height (9-inch cone)

$$
z_{1}=0+(-60)+20+100=60
$$

$\mathrm{z}_{2}=10+20+60+20=110$

$\mathrm{Z}_{3}=20+(-20)+20+60=80$

$z_{4}=10+20+20+20=70$

Figure 9. Computational Technique to Compute Sum of Squares for a Four by Four latin Square 
Table 3. Generalized Analysis of Variance for Four by Four Latin Square With No Repeated Runs

\begin{tabular}{lllll}
\hline $\begin{array}{l}\text { Source of } \\
\text { Variation }\end{array}$ & $\begin{array}{l}\text { Degrees of } \\
\text { Freedom }\end{array}$ & $\begin{array}{l}\text { Sum of } \\
\text { Squares }\end{array}$ & $\begin{array}{l}\text { Mean } \\
\text { Square }\end{array}$ & $\begin{array}{l}\text { Expected } \\
\text { Mean Square }\end{array}$ \\
\hline Total & 15 & Tss & & \\
$X$ & 3 & Xss & Xms $=X s s / 3$ & $\sigma_{\mathrm{R}}^{2}+4 \sigma_{\mathrm{X}}^{2}$ \\
$\mathrm{Y}$ & 3 & Yss & Yms $=Y s s / 3$ & $\sigma_{\mathrm{R}}^{2}+4 \sigma_{\mathrm{Y}}^{2}$ \\
$Z$ & 3 & Zss & Zms $=Z s s / 3$ & $\sigma_{\mathrm{R}}^{2}+4 \sigma_{\mathrm{Z}}^{2}$ \\
Error* & 6 & Ess & Ems $=$ Ess $/ 6$ & $\sigma_{\mathrm{R}}^{2}$ \\
\hline * residual & & & & \\
\hline
\end{tabular}

deviations from $Y$ and $Z$ nominals, respectively. The results from the AOVs are used to determine CMM measurement capability. (The aforementioned analyses can be programmed into the microcomputer interfaced with the CMM; a procedure that requires 300 to 400 programming steps. Calculations could begin as soon as the first data point is taken, and the complete analysis would be finished almost as soon as the last data point was taken. Otherwise, about one hour is required, using a non-programmable scientific hand calculator.)

Precision is defined as $\pm 2 \hat{\sigma}_{\mathrm{CMMR}}$, where $\hat{\sigma}_{\mathrm{CMMR}}=\sqrt{\sigma_{\mathrm{XR}}^{2}+\sigma_{\mathrm{YR}}^{2}+\sigma_{\mathrm{ZR}}^{2}}$ For the data in this example, $\hat{\sigma}_{\text {CMMR }}=\sqrt{1250+1467+2490}=\sqrt{5207}=$ $72 \mu$ in. $=0.000072$ in. Therefore, precision $= \pm 0.000144$ in. 
Table 4. Deviation From X Nominal ( $\mu$ in. ${ }^{2}$ )

\begin{tabular}{|c|c|c|c|c|}
\hline $\begin{array}{l}\text { Source of } \\
\text { Variation }\end{array}$ & $\begin{array}{l}\text { Degrees of } \\
\text { Freedom }\end{array}$ & $\begin{array}{l}\text { Sum of } \\
\text { Squares }\end{array}$ & $\begin{array}{l}\text { Mean } \\
\text { Square }\end{array}$ & $\begin{array}{l}\text { Expected } \\
\text { Mean Square }\end{array}$ \\
\hline Total & 15 & 18200 & & \multirow{5}{*}{$\begin{array}{l}\sigma_{\mathrm{RX}}^{2}+4 \sigma_{\mathrm{X}}^{2} \\
\sigma_{\mathrm{RX}}^{2}+4 \sigma_{\mathrm{Y}}^{2} \\
\sigma_{\mathrm{RX}}^{2}+4 \sigma_{\mathrm{Z}}^{2} \\
\sigma_{\mathrm{RX}}^{2}\end{array}$} \\
\hline $\mathrm{X}$ & 3 & 2350 & 783 & \\
\hline $\mathrm{Y}$ & 3 & 8000 & 2667 & \\
\hline $\mathrm{z}$ & 3 & 350 & 117 & \\
\hline Error* & 6 & 7500 & 1250 & \\
\hline
\end{tabular}

$\star$ residual

Component Estimation

$\hat{\sigma}_{\mathrm{RX}}^{2}=1250$

$\hat{\sigma}_{\mathrm{Z}}^{2}=0$

$\hat{\sigma}_{\mathrm{Y}}^{2}=354$

$\hat{\sigma}_{\mathrm{X}}^{2}=0$

$\hat{\sigma}_{\mathrm{XDEV}}^{2}=1604$

Machine capability is defined as $\pm 2 \hat{\sigma}_{\mathrm{CMM}}$, where $\hat{\sigma}_{\mathrm{CMM}}=\sqrt{\hat{\sigma}_{\mathrm{XDEV}}^{2}+}$ $\hat{\sigma}_{\mathrm{YDEV}}^{2}+\hat{\sigma}_{\mathrm{ZDEV}}^{2}$. For the data in this example, $\hat{\sigma}_{\mathrm{CMM}}=\sqrt{1604+}$ $\overline{1999+\overline{3190}}=\sqrt{6793}=82 \mu \mathrm{in} .=0.000082 \mathrm{in}$. Therefore, machine capability $= \pm 0.000164$ in.

This information is then used to determine whether the machine has the capability of correctly classifying parts submitted to be inspected. Parts whose "specifications" or tolerance requirements 
Table 5. Deviations From Y Nominal ( $\mu$ in. ${ }^{2}$ )

\begin{tabular}{lcccl}
\hline $\begin{array}{l}\text { Source of } \\
\text { Variation }\end{array}$ & $\begin{array}{l}\text { Degrees of } \\
\text { Freedom }\end{array}$ & $\begin{array}{l}\text { Sum of } \\
\text { Squares }\end{array}$ & $\begin{array}{l}\text { Mean } \\
\text { Square }\end{array}$ & $\begin{array}{l}\text { Expected } \\
\text { Mean Square }\end{array}$ \\
\hline Total & 15 & 28400 & & \\
$\mathrm{X}$ & 3 & 7600 & 2533 & $\sigma_{\mathrm{RY}}^{2}+4 \sigma_{\mathrm{X}}^{2}$ \\
$\mathrm{Y}$ & 3 & 5200 & 1733 & $\sigma_{\mathrm{RY}}^{2}+4 \sigma_{\mathrm{Y}}^{2}$ \\
$\mathrm{Z}$ & 3 & 6800 & 2267 & $\sigma_{\mathrm{RY}}^{2}+4 \sigma_{\mathrm{Z}}^{2}$ \\
Error* & 6 & 8800 & 1467 & $\sigma_{\mathrm{RY}}^{2}$ \\
\hline
\end{tabular}

*residual

Component Estimation

$\hat{\sigma}_{\mathrm{RY}}^{2}=1467$

$\hat{\sigma}_{\mathrm{Z}}^{2}=200$

$\hat{\sigma}_{\mathrm{Y}}^{2}=66$

$\hat{\sigma}_{\mathrm{Z}}^{2}=266$

$\hat{\sigma}_{\mathrm{YDEV}}^{2}=1999$

are less than or close to the machine tolerance cannot be adequately inspected by using the machine; if they are inspected, misclassification may result. To illustrate, suppose, for example, that the diameter of a critical part has a tolerance requirement of \pm 0.000164 in. For the measurement machine, in the aforementioned study, the capability is \pm 0.000164 in. Based on these tolerances, if the variation in the process is such that the process is making five percent defective parts, then 14 percent 
Table 6. Deviations From $z$ Nominal ( $\mu$ in. ${ }^{2}$ )

\begin{tabular}{lcccc}
\hline $\begin{array}{l}\text { Source of } \\
\text { Var1ation }\end{array}$ & $\begin{array}{l}\text { Degrees of } \\
\text { Freedom }\end{array}$ & $\begin{array}{l}\text { Sum of } \\
\text { Squares }\end{array}$ & $\begin{array}{l}\text { Mean } \\
\text { Square }\end{array}$ & $\begin{array}{l}\text { Expected } \\
\text { Mean Square }\end{array}$ \\
\hline Total & 15 & 43844 & & \\
$\mathrm{X}$ & 3 & 14569 & 4856 & $\sigma_{\mathrm{RZ}}^{2}+4 \sigma_{\mathrm{X}}^{2}$ \\
$\mathrm{Y}$ & 3 & 5569 & 1856 & $\sigma_{\mathrm{RZ}}^{2}+4 \sigma_{\mathrm{Y}}^{2}$ \\
$\mathrm{Z}$ & 3 & 8769 & 2923 & $\sigma_{\mathrm{RZ}}^{2}+4 \sigma_{\mathrm{Z}}^{2}$ \\
Error* & 6 & 14937 & 2490 & $\sigma_{\mathrm{RZ}}^{2}$ \\
\hline
\end{tabular}

*residual

Component Estimation

$\hat{\sigma}_{\mathrm{RZ}}^{2}=2490$

$\hat{\sigma}_{\mathrm{Z}}^{2}=108$

$\hat{\sigma}_{\mathrm{Y}}^{2}=0$

$\hat{\sigma}_{\mathrm{X}}^{2}=592$

$\underline{\hat{\sigma}_{\mathrm{ZDEV}}^{2}}=3190$

of the parts will be misclassified because of the magnitude of machine accuracy. Then, suppose that, based on this information, this magnitude of accuracy was determined to be unacceptable for this part. By using the techniques described in the subsequent section, it was determined that there was yaw in the $\mathrm{x}$-axis. The CMM was then adjusted and its capability was determined to be \pm 0.000041 in. Now, the misclassification error rate would be only two percent. Therefore, knowledge of the measurement capability of a CMM can be used to determine whether the CMM can correctly measure inspection items. 


\section{Identification of Errors in Machine Geometry}

The Latin square AOV has another important use in evaluating CMMs. If a CMM is out of calibration or exhibits excessive variation or both, it is desirable to make the necessary adjustments to bring the CMM back into calibration (reduce its inaccuracy). Currently, the approach to determine the necessary adjustments is based on experience and trial and error. An advantage of the LS3DBP is that the analysis of variance, from which quantitative estimates of the factors affecting machine measurement capabilities are obtained, can also be used to identify sources of error in CMM geometry. A study involving simulated data from a cantilever design coordinate measuring machine indicates that the type of error-yaw, pitch, roll in $\mathrm{X} / \mathrm{Y} / \mathrm{X}$, point-to-point positioning in $\mathrm{X} / \mathrm{Y} / \mathrm{Z}$, and out-of-squareness ( $\mathrm{XY}, \mathrm{XZ} /$ and $\mathrm{YX}$ ) can be identified by proper interpretation of the Latin square analysis of variance. ${ }^{2}$ The results of this study are summarized in Table 7. Each source of error produces a unique pattern regarding which deviations from nominal are affected, which axis affects the deviation, and the form (linear, quadratic and/or cubic) that the effect of axis movement has. From Table 7 , yaw in the $X$-axis is identified by linear and cubic $\left(\mathrm{L}_{1, c}\right)$ effects on $\mathrm{X}$ deviations from nominal when movement along the $\mathrm{X}$-axis is present. Tn addition, movement along the $\mathrm{X}$-axis causes a small quadratic effect on deviations from $Y$ nominal. 
Table 7. Summary of Analysis Results on Simulated Data From Cantilever Design CMM

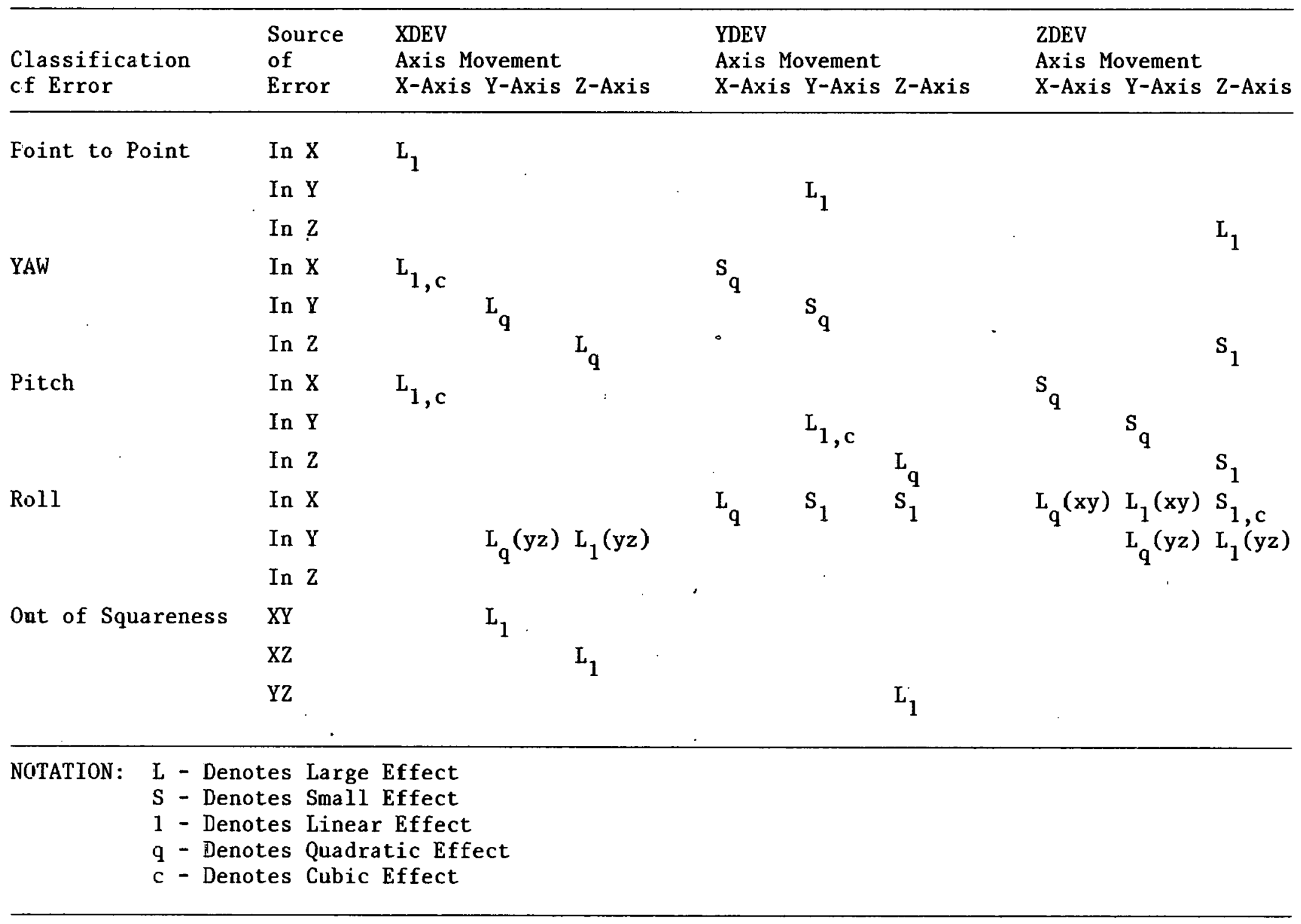


The determination of the linear, quadratic, and cubic effects is as follows. Consider the AOV for deviations from $\mathrm{X}$ nominal in Table 4. The three degrees of freedom for movement along each axis can be separated into three independent effects--linear, quadratic, and cubic. This separation is achieved by the use of orthogonal comparisons for equally spaced data. ${ }^{3}$ Figure 10 illustrates the coefficients and divisors with the computational procedure to obtain the three effects. A complete separation of the axes ( $X, Y$, and $Z$ ) sums of squares is in Table 8.

To judge which sources are significant, consider first only these axes whose mean square is of some predetermined magnitude greater than the error mean square. The predetermined magnitude can be a tabulated $F$ to determine statistical significance. ${ }^{4}$ (Regardless of the statistical significance, this magnitude should be judged for practical significance relative to specified CMM precision.) A conservative test of significance is to consider those sources whose mean square is more than twice the magnitude of error mean square. By applying the conservative test to the mean square in Table 8 , the $Y$-axis is significant and $Y_{1}$ and $Y_{c}$ would be candidates. In Table 9, no axes are significant. In Table 10, only the $\mathrm{Y}$-axis approaches twice the error mean square, and $\mathrm{Y}_{1}$ is a potential candidate. 
Coefficient and divisors for separation of sums of squares of axis movement for data from LS3DBP.

\begin{tabular}{|c|c|c|c|}
\hline Contrast & $\begin{array}{l}\text { Degrees of } \\
\text { Freedom }\end{array}$ & Coefficient & Divisor \\
\hline$\overline{\text { Linear (1) }}$ & 1 & $\overline{-3,-1,+1,+3}$ & $\overline{20}$ \\
\hline Quadratic (q) & 1 & $+1,-1,-1,+1$ & 4 \\
\hline Cubic (c) & 1 & $-1,+3,-3,+1$ & 20 \\
\hline
\end{tabular}

Computational Procedure

1. Take the 4 totals for the $\mathrm{X}$-axis (Figure 9) (Deviation from $\mathrm{X}$ nomina1)

$$
\begin{array}{llll}
x_{1} & x_{2} & \frac{x_{3}}{30} & \frac{x_{4}}{160}
\end{array}
$$

$x_{1}=[-3(60)-1(70)+1(30)+3(160)]^{2} /(20)(4)=845$

$\mathrm{x}_{\mathrm{q}}=[+1(60)-1(70)-1(30)+1(160)] /(4)(4)=900$

$x_{c}=[-1(60)+3(70)-3(30) .+1(160)]^{2} /(20)(4)=605$

2. The previous three sums of square equal the sums of squares for $X$ in Table A-5 $(845+900+605=2350)$

3. For the effect of $\mathrm{Y}$-axis on deviation from $\mathrm{X}$ nominal

$$
\frac{Y_{1}}{40} \quad \frac{Y_{2}}{-40} \quad \frac{Y_{3}}{200} \quad \frac{Y_{4}}{120}
$$

$Y_{1}=[-3(40)-1(-40)+1(200)+3(120)]^{2} /(20)(4)=2880$

$\mathrm{Y}_{\mathrm{q}}=[+1(40)-1(-40)-1(200)+1(120)]^{2} /(4)(4)=0$

$Y_{c}^{q}=[-1(40)+3(-40)-3(200)+1(120)]^{2} /(20)(4)=5120$

4. For separation of contrasts for $\mathrm{Z}$-axis on deviation from $\mathrm{X}$ nominal

$$
\frac{\mathrm{z}_{1}}{60} \quad \frac{\mathrm{z}_{2}}{110} \quad \frac{\mathrm{z}_{3}}{80} \quad \frac{\mathrm{z}_{4}}{70}
$$

$\mathrm{Y}_{1}=[-3(60)-1(110)+1(80)+3(70)]^{2} /(20)(4)=0$

$\mathrm{Y}_{\mathrm{q}}=[+1(60)-1(110)-1(80)+1(70)]^{2} /(4)(4)=225$

$\mathrm{Y}_{\mathrm{c}}=[-1(60)+3(110)-3(80)+1(70)]^{2} /(20)(4)=125$

The complete analysis breakdown is presented in Table 8 .

Figure 10. Coefficient and Divisors for Separation of Sums of Squares of Axis Movement for Data From LS3DBP and Computational Procedure 
If the previous data had been taken on a cantilever design CMM, the candidates $\left(Y_{I}\right.$ and $Y_{c}$ on deviations from $X$ nominal and $Y_{I}$ on deviations from $Z$ nominal) could be compared to the results in Table 7 to determine the source of errors in machine geometry. However, the data that were used in this discussion to demonstrate the analysis procedure is from a bridge design CMM. A comparison is not meaningful because the patterns of deviations are expected to be different for each of the five major design configurations (Appendix B). The philosophy used to evaluate error identification for a cantilever design can be applied to other CMM design configurations to develop results for each configuration, as shown in Table 7. To date, only the results of the cantilever design have been determined. An investigation to define error patterns in other design configurations is underway.

\section{CONCLUSIONS}

Coordinate measuring machines are an important factor in meeting the challenge to improve productivity in the field of quality assurance. These machines can fulfill this function only if they are measuring to their designed capabilities. The Latin square three-dimensional ball plate (LS3DBP) can be used to determine the measurement capabilities of a CMM in three dimensions. Data 
Table 8. Expanded Analysis of Variance for Deviations From X Nominal for Separation of Axis Sum of Squares Into Three Orthogonal Contrasts for Use in Identification of Sources of Error in Machine Geometry

\begin{tabular}{ccrr}
\hline $\begin{array}{c}\text { Source of } \\
\text { Variation }\end{array}$ & $\begin{array}{l}\text { Degrees of } \\
\text { Freedom }\end{array}$ & $\begin{array}{c}\text { Sum of } \\
\text { Squares }\end{array}$ & $\begin{array}{c}\text { Mean } \\
\text { Square }\end{array}$ \\
\hline Total & 15 & 18200 & \\
$\mathrm{X}_{1}$ & 3 & 2350 & 783 \\
$\mathrm{X}_{\mathrm{q}}$ & 1 & 845 & 845 \\
$\mathrm{X}_{\mathrm{c}}$ & 1 & 900 & 900 \\
$\mathrm{Y}$ & 1 & 605 & 605 \\
$\mathrm{Y}_{1}$ & 3 & 8000 & 2667 \\
$\mathrm{Y}_{\mathrm{q}}$ & 1 & 2880 & 2880 \\
$\mathrm{Y}_{\mathrm{c}}$ & 1 & 0 & 0 \\
$\mathrm{Z}$ & 1 & 5120 & 5120 \\
$\mathrm{Z}_{1}$ & 3 & 350 & 117 \\
$\mathrm{Z}_{\mathrm{q}}$ & 1 & 0 & 0 \\
$\mathrm{Z}_{\mathrm{c}}$ & 1 & 225 & 225 \\
Error & 1 & 125 & 125 \\
I & 6 & 7500 & 1250 \\
residual & & & \\
\hline
\end{tabular}

obtained by use of the LS3DBP are statistically balanced and therefore can be analyzed quickly by using the analysis of variance technique. The information that can be determined from the analyses followe: 
Table 9. Expanded Analysis of Variance for Deviations From $Y$ Nominal for Separation of Axis Sum of Squares Into Three Orthogonal Contrasts for Use in Identification of Sources of Error in Machine Geometry

\begin{tabular}{ccrr}
\hline $\begin{array}{c}\text { Source of } \\
\text { Variation }\end{array}$ & $\begin{array}{l}\text { Degrees of } \\
\text { Freedom }\end{array}$ & $\begin{array}{l}\text { Sum of } \\
\text { Squares }\end{array}$ & $\begin{array}{c}\text { Mean } \\
\text { Square }\end{array}$ \\
\hline Total & 15 & 28400 & \\
$\mathrm{X}_{1}$ & 3 & 7600 & 2533 \\
$\mathrm{X}_{\mathrm{q}}$ & 1 & 2000 & 2000 \\
$\mathrm{X}_{\mathrm{c}}$ & 1 & 3600 & 3600 \\
$\mathrm{Y}$ & 1 & 2000 & 2000 \\
$\mathrm{Y}_{1}$ & 3 & 5200 & 1733 \\
$\mathrm{Y}_{\mathrm{q}}$ & 1 & 1280 & 1280 \\
$\mathrm{Y}_{\mathrm{c}}$ & 1 & 0 & 0 \\
$\mathrm{Z}^{\mathrm{Z}}$ & 1 & 3920 & 3920 \\
$\mathrm{Z}_{1}$ & 3 & 6800 & 2267 \\
$\mathrm{Z}_{\mathrm{q}}$ & 1 & 320 & 320 \\
$\mathrm{Z}_{\mathrm{c}}$ & 1 & 3600 & 3600 \\
Error* & 1 & 2880 & 2880 \\
\hline \multirow{*}{*}{ residual } & 6 & 8800 & 1467 \\
\hline
\end{tabular}

- Precision;

- Systematic error (bias);

- Capability; and

- Identification of sources of error in CMM geometry. 
Table 10. Expanded Analysis of Variance for Deviations From $Z$ Nominal for Separation of Axis Sum of Squares Into Three Orthogonal Contrasts for Use in Identification of Sources of Error in Machine Geometry

\begin{tabular}{|c|c|c|c|}
\hline $\begin{array}{l}\text { Source } \\
\text { Variation }\end{array}$ & $\begin{array}{l}\text { Degrees of } \\
\text { Freedom }\end{array}$ & $\begin{array}{l}\text { Sum of } \\
\text { Squares }\end{array}$ & $\begin{array}{l}\text { Mean } \\
\text { Square }\end{array}$ \\
\hline Total & 15 & 43844 & \\
\hline $\mathrm{X}$ & 3 & 5569 & 1856 \\
\hline $\mathrm{x}_{1}$ & 1 & 61 & 61 \\
\hline$x_{q}$ & 1 & 2257 & 2257 \\
\hline$x_{c}$ & 1 & 3251 & 3251 \\
\hline$Y$ & 3 & 14569 & 4856 \\
\hline$Y_{1}$ & 1 & 11762 & 11762 \\
\hline$Y_{q}$ & 1 & 2256 & 2256 \\
\hline$Y_{c}$ & 1 & 551 & 551 \\
\hline Z & 3 & 8769 & 2923 \\
\hline$z_{1}$ & 1 & 1 & 1 \\
\hline$z_{q}$ & 1 & 8557 & 8557 \\
\hline $\mathrm{z}_{\mathrm{c}}$ & 1 & 211 & 211 \\
\hline Error & 6 & 14937 & 2490 \\
\hline
\end{tabular}

This information provides a quantitative basis to determine whether the CMM can adequately measure a product and to assure that the decision to accept product has a high probability of being correct. 


\section{REFERENCES}

1 "CMM Stands for Productivity Improvement," Quality, Volume 18, Number 3, March 1979, pp 38-54.

${ }^{2}$ L. L. Jones, J. V. Grice, and K. E. Moser, Use of Latin Square Analysis of Variance to Identify Sources of Error in Cantilever Design Coordinate Measuring Machines (Final Report). Bendix Kansas City: BDX-613-2679, October 1981 (Available from NTIS).

${ }^{3}$ R. G. Steel and J. H. Torrie, Principles and Procedures of Statistics. New York: McGraw Hill, 1960, pp 222.

${ }^{4}$ Steel and Torrie, pp 103-104. 
Information about various types of coordinate measuring machines can be obtained from these companies:

Digital Electronic Automation, Incorporated 36310 Ecorse Road Romulus, MI 48174

Mitutoyo Instrument Center

14847-B Proctor Avenue

City of Industry, CA 91746

Boice Division

Mechanical Technology, Incorporated

968 Albany-Shaker Road

Latham, NY 12210

Carl Zeiss, Incorporated

IMT Division

1 Skyline Drive

Hawthorne, NY 10532

Bendix Automation \& Measurement Division

Springfield and Thomas Streets

Dayton, OH 45401 


\section{Appendix B \\ CLASSIFICATIONS OF CMMS}

(The material in this appendix has been taken from an initial draft of ASME B89.1.12 Committee--CMM Industrial Standard.

This material is included for general information regarding various types of CMMs. Permission to incorporate this material was granted by Erwin Loewen, Chairman of ASME B89 Committee.) 
CLASSIFICATION - The following descriptions relate to coordinate Measuring Devices employing moving mechanical components, the relative motions of which are measured by a suitable encoding means. The devices incorporate probing components utilized to interface with the object being measured, which is restrained on a support table. Variations in the methods of moving the mechanical components, the encoding means and the probing components may be varied within each classification to further expand the types of Coordinate Measuring Devices.

CANTILEVER - A measuring device employing three mechanical components moving along mutually perpendicular axes. The probing device is attached to the component with motion in the vertical direction, which in turn is attached to the first of the two horizontal components. The first is fixed to: the second at one end ouly, in cantilever fashion, over the suppurt table. (see Fig. A)

BRIDGE - A measuring device employing three mechanical components moving along mutually perpendicular axes. The probing device is attached to the component with motion in the vertical direction, which in turn is attached to the first of the two horizontal components. The first is attached to the second at two locations forming a bridge over the support table. (see Fig. B)

COLUMN - A measuring device employing one mechanical component moving in the vertical direction to which the probing device is attached. The support table is movable in two mutually perpendicular horizontal directions. (see Fig. C)

HORIZONTAL ARM - A measuring device employing three mechanical components moving along mutually perpendicular axes. The probing device is attached to the first component movable in the horizontal direction. This component is attached to the vertical component in cantilever fashion over the support table. The vertical component is attached to the second horizontal component. (see Fig. D)

GANTRY - A measuring device employing three mechanical components moving along mutually perpendicular axes. The probing device is attached to the component moving in the vertical direction, which in turn is attached to the first horizontal component. The first component is attached to the second horizontal in two locations bridging the support table (support jacks) in a location elevated above the support table. (see Fig. E)

OTHER - Any machine utilizing axes configuration different than stated in the above categories. 


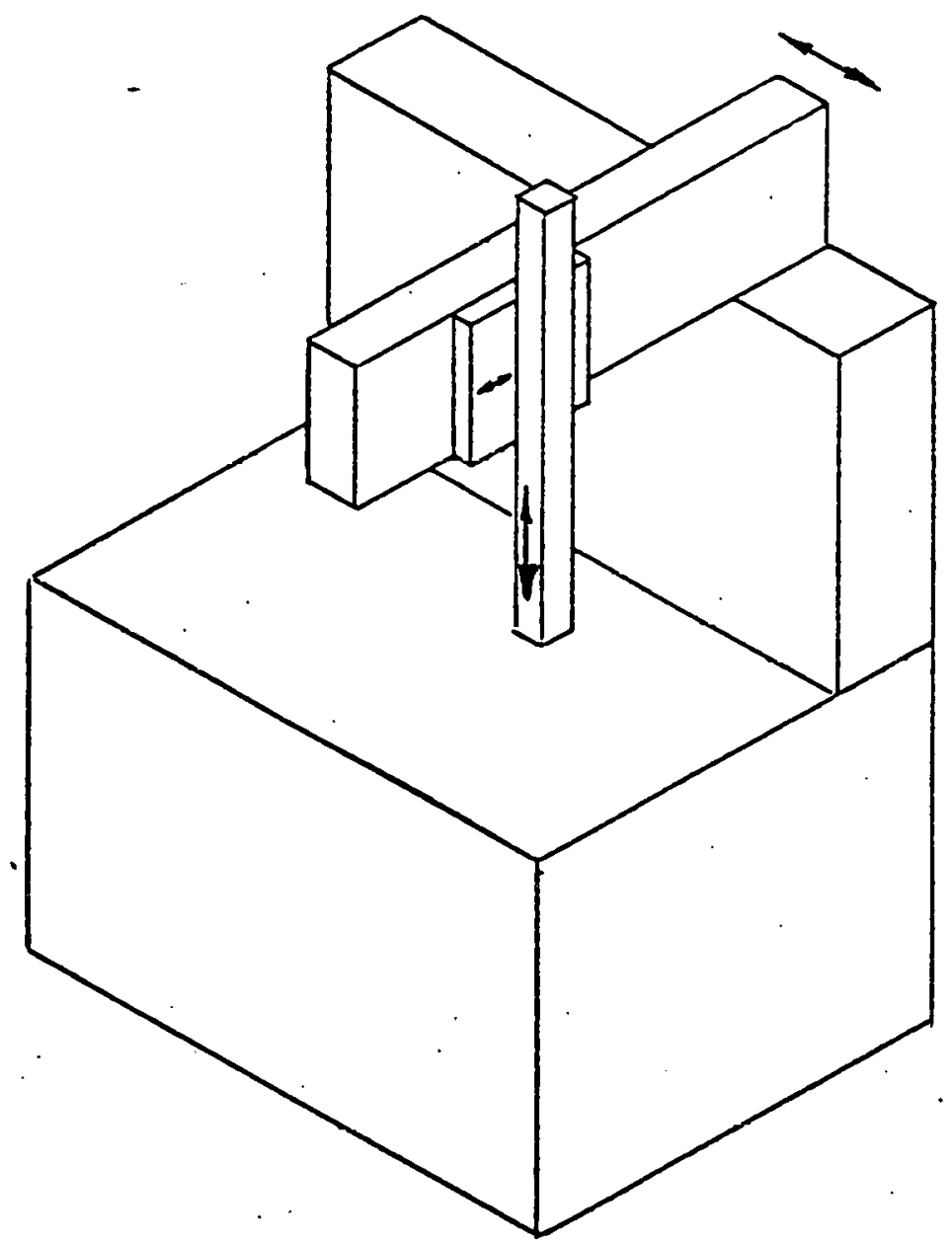

FIG. "A" 


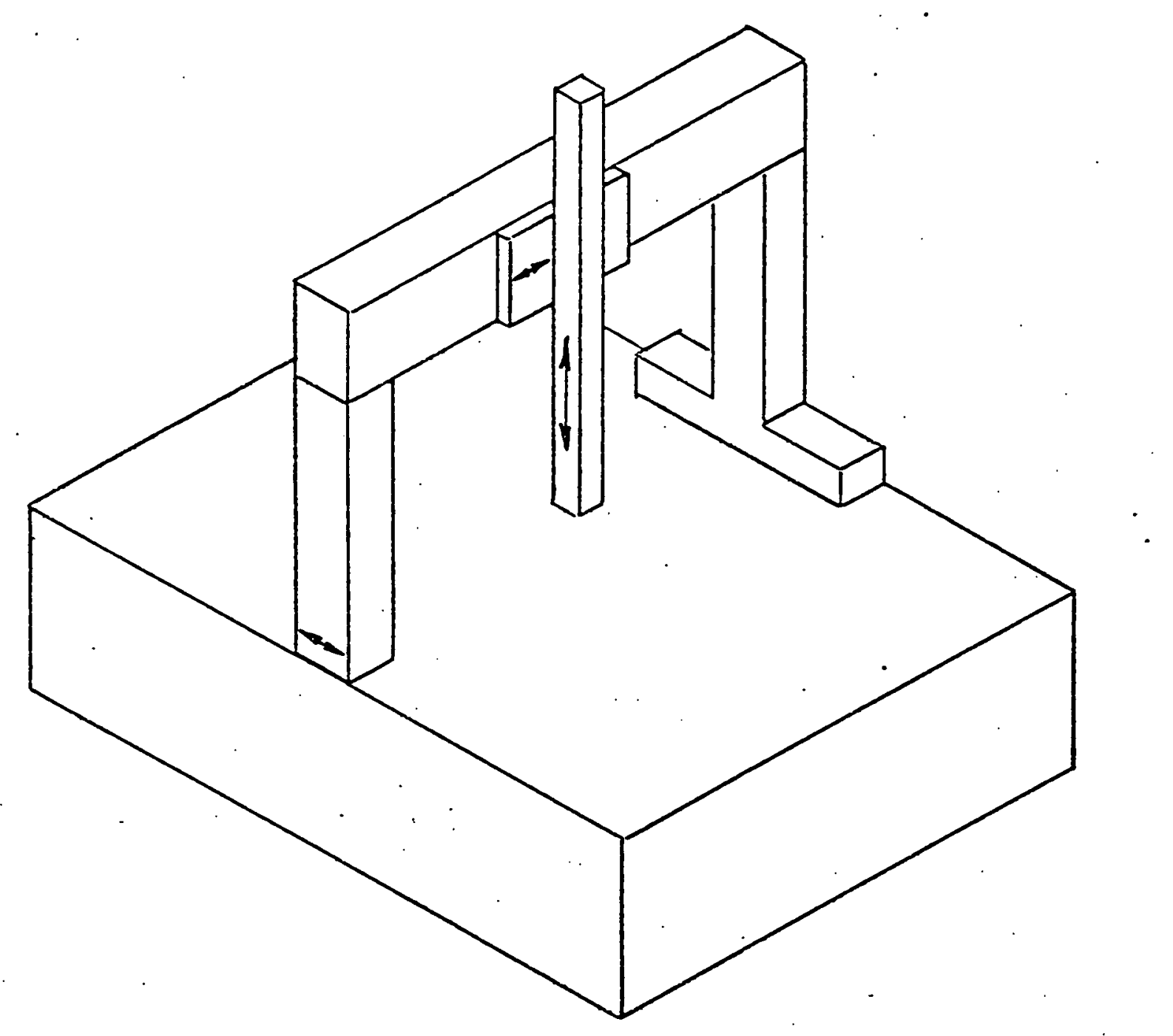

FIG. "B" 


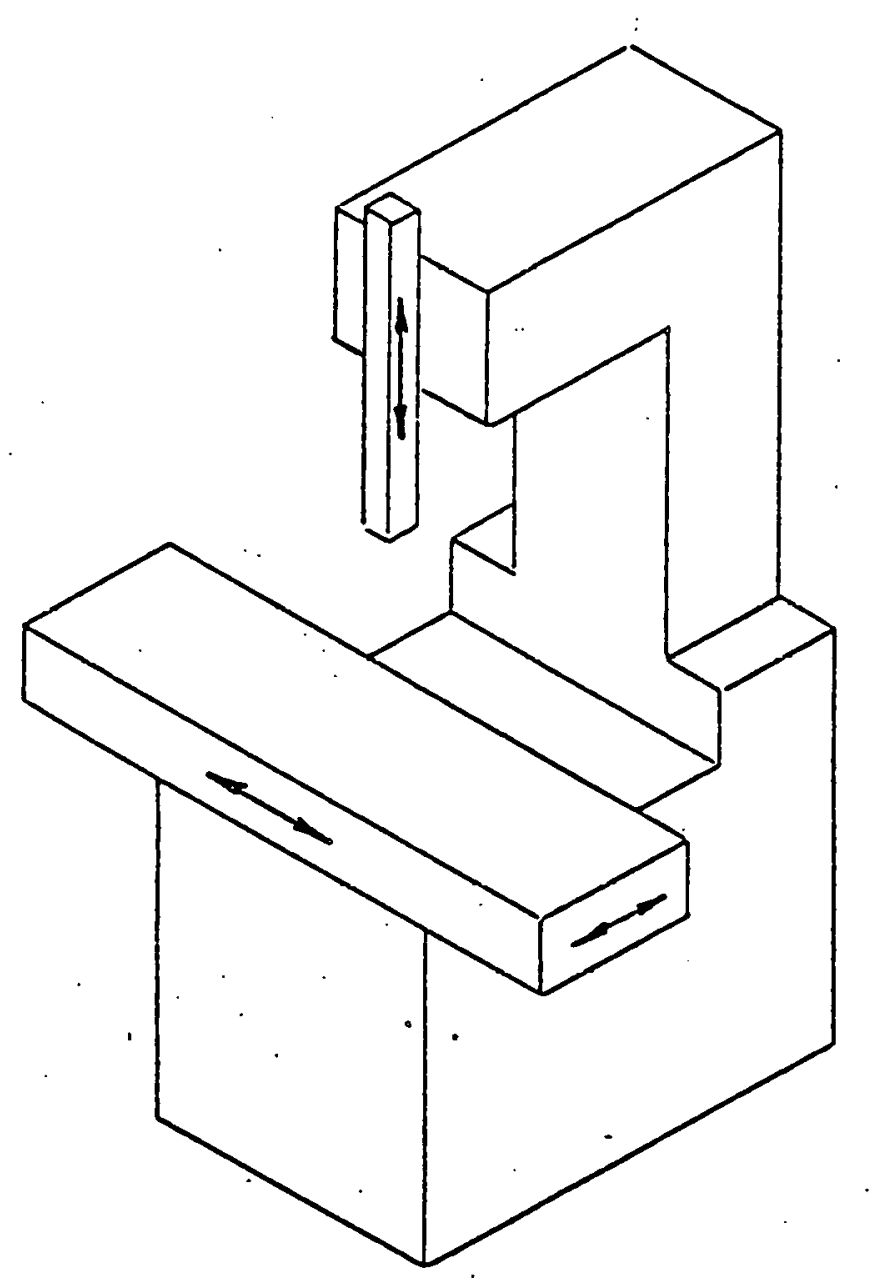

FIG. "C" 


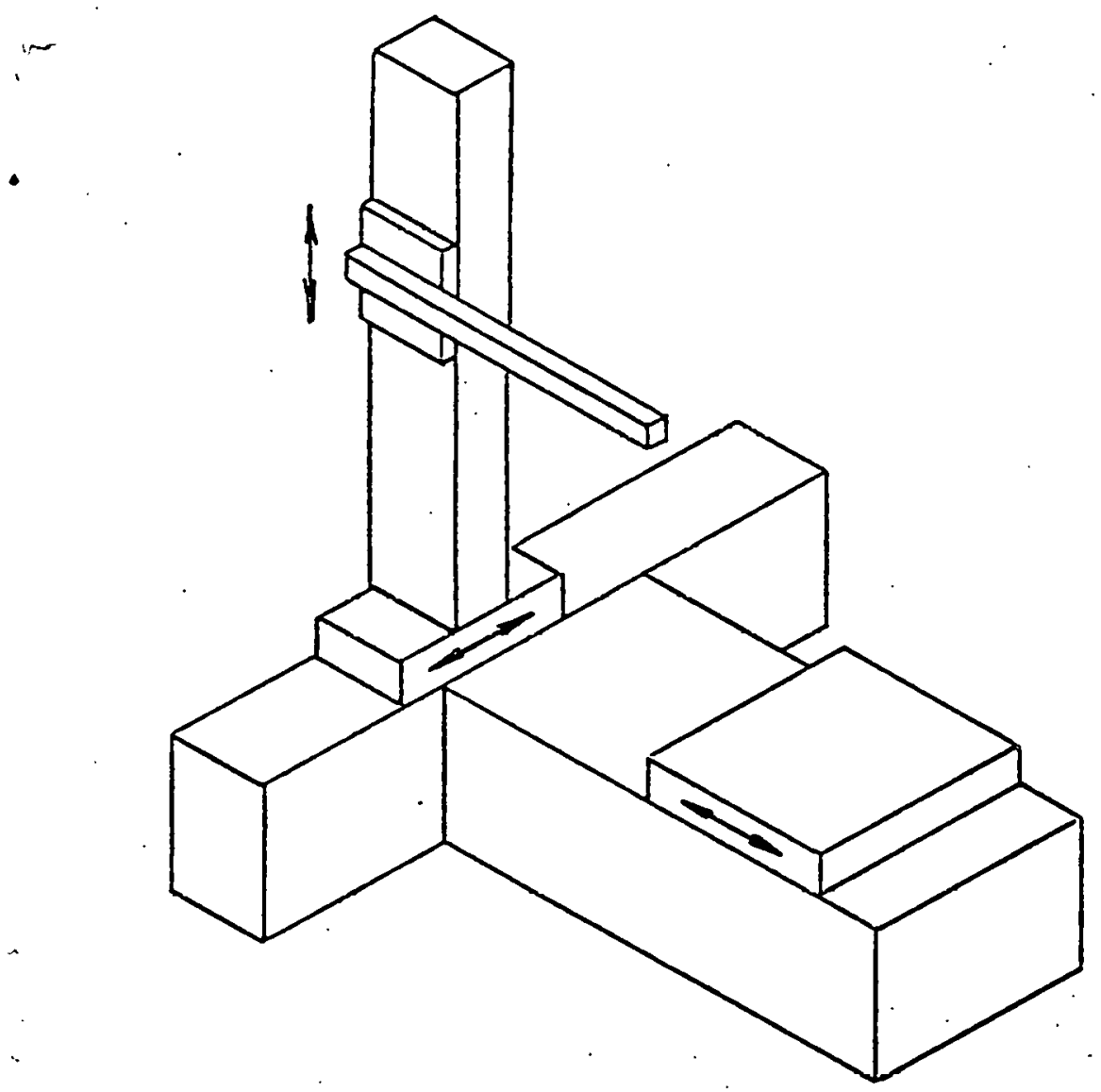

FIG. "D" 


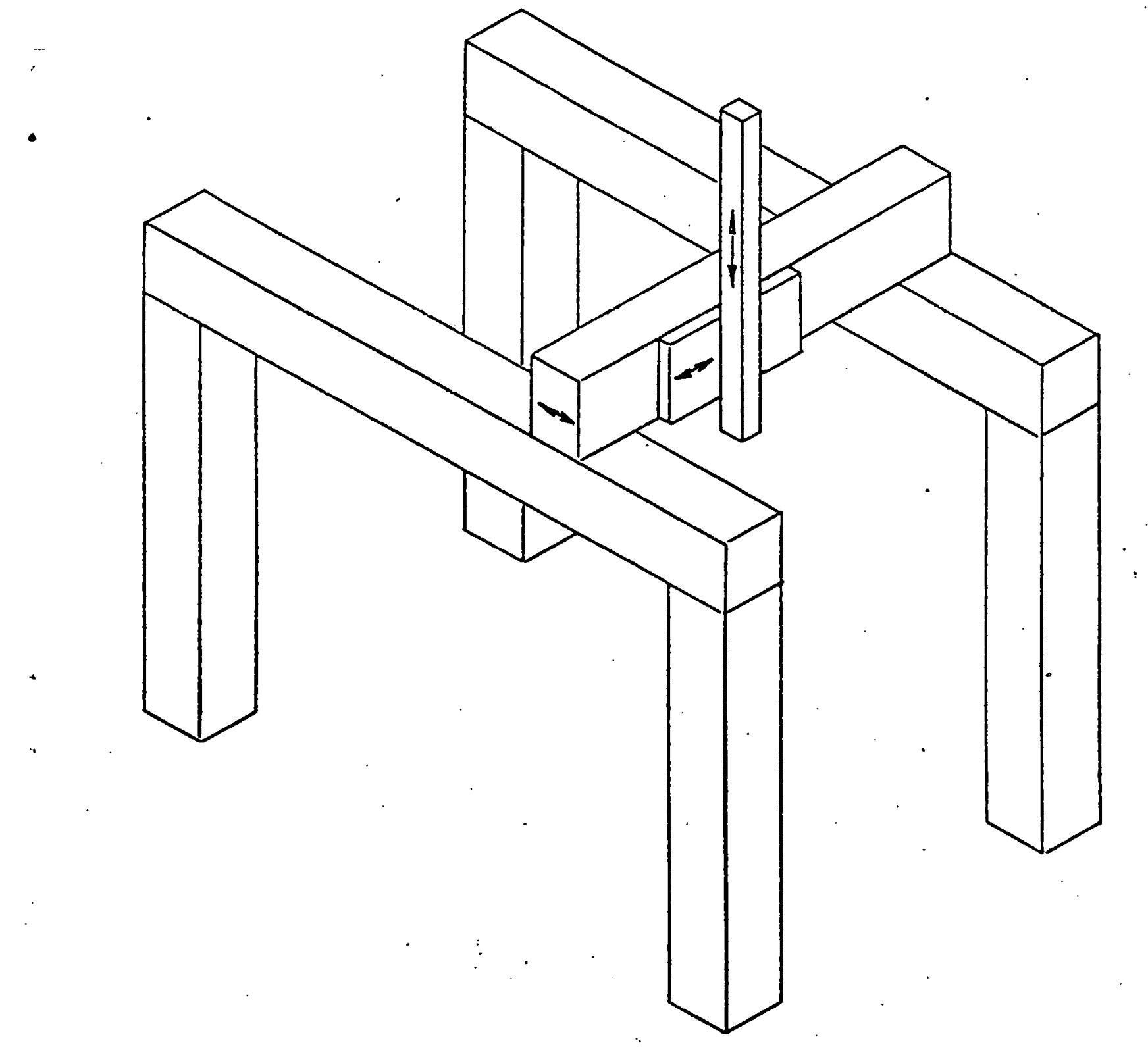

FIG. "E" 
$\mathrm{BDX}-613-2682$

LATIN SQUARE THREE-DIMENSIONAL BALL PLATE, L. Jones, Topical, October 1981

Electronic coordinate measuring machines (CMM) represent the state-of-the-art in automatic three-dimensional measuring equipment. Current techniques for determining measurement capability of CMM are complex. A Latin square three-dimensional ball plate has been developed to evaluate the measurement capability of a CMM in three dimensions. The unique allocation of tooling balls in an XYZ space permits data to bel obtained that is balanced statistically and can 1 be analyzed quickly by using the analysis of

SPECIAL PROJECTS: Ball Plate Measurement

LATIN SQUARE THREE-DIMENSIONAL BALL PLATE, L. Jones, Topical, BDX-613-2682, October 1981

Electronic coordinate measuring machines (CMM) represent the state-of-the-art in automatic three-dimensional measuring equipment. Current techniques for determining measurement capa-. bility of CMM are complex. A Latin square three-dimensional ball plate has been developed to evaluate the measurement capability of a CMM in three dimensions. The unique allocation of tooling balls in an XYZ space permits data to be obtained that is balanced statistically and can be analyzed quickly by using the analysis of

LATIN SQUARE THREE-DIMENSIONAL BALL PLATE, L. Jones, Topical, BDX-613-2682, October 1981

Electronic coordinate measuring machines (CMM) represent the state-of-the-art in automatic three-dimensional measuring equipment. Current techniques for determining measurement capability of CMM are complex. A Latin square three-dimensional ball plate has been developed to evaluate the measurement capability of a CMM in three dimensions. The unique allocation of tooling balls in an XYZ space permits data to bel obtained that is balanced statistically and can 1 be analyzed quickly by using the analysis of 
variance techniques for a Latin square experimental design. The analysis of this data is used to determine quantitative measures of the precision and systematic error of CMM in three dimensions and to identify sources of error in machine geometry. This ball plate currently is used to determine CMM capability and to identify source(s) of error in machine geometry. This device requires 70 percent less time than some conventional techniques to estimate CMM capability in three dimensions.

variance techniques for a Latin square experimental design. The analysis of this data is used to determine quantitative measures of the precision and systematic error of CMM in three dimensions and to identify sources of error in machine geometry. This ball plate currently is used to determine CMM capability and to identify source(s) of error in machine geometry. This device requires 70 percent less time than some conventional techniques to estimate CMM capability in three dimensions.

variance techniques for a Latin square experimental design. The analysis of this data is used to determine quantitative measures of the precision and systematic error of CMM in three dimensions and to identify sources of error in machine geometry. This ball plate currently is used to determine CMM capability and to identify source(s) of error in machine geometry. This device requires 70 percent less time than some conventional techniques to estimate CMM capability in three dimensions. 